\title{
Donor- and/or Acceptor-Substituted Expanded Radialenes: Theory, Synthesis, and Properties
}

\author{
Sharwatie Ramsaywack, ${ }^{\perp, \dagger}$ Sila Karaca, ${ }^{\perp, \ddagger}$ Mojtaba Gholami, ${ }^{\dagger}$ Adrian H. Murray, ${ }^{\dagger}$ Frank Hampel, ${ }^{\S}$ \\ Robert McDonald, ${ }^{\dagger}$ Nuran Elmaci, ${ }^{*}{ }^{\ddagger}$ Hans Peter Lüthi, ${ }^{\prime \prime}$ and Rik R. Tykwinski*, ${ }^{\S}$ \\ ${ }^{\dagger}$ Department of Chemistry, University of Alberta, Edmonton, Alberta T6G 2G2, Canada \\ ${ }^{\ddagger}$ Department of Chemistry, İzmir Institute of Technology, Urla, 35430 İzmir, Turkey \\ ${ }^{\S}$ Department of Chemistry and Pharmacy \& Interdisciplinary Center of Molecular Materials (ICMM), \\ Friedrich-Alexander-Universität Erlangen-Nürnberg (FAU), Henkestrasse 42, 91054 Erlangen, Germany \\ "Department of Chemistry and Applied Biosciences, ETH Zürich, Vladimir-Prelog-Weg 2, 8093 Zürich, Switzerland
}

\section{Supporting Information}

ABSTRACT: The synthesis of donor- (D) and/or acceptor (A)-expanded [4] radialenes has been developed on the basis of readily available dibromoolefin (7), tetraethynylethene (10 and 20), and vinyl triflate (12) building blocks. The successful formation of $\mathrm{D} / \mathrm{A}$ radialenes relies especially on (1) effective use of a series alkynyl protecting groups, (2) Sonogashira crosscoupling reactions, and (3) the development of ring closing reactions to form the desired macrocyclic products. The expanded [4] radialene products have been investigated by spectroscopic (UV-vis absorption and emission) and quantum chemical computational methods (density func-

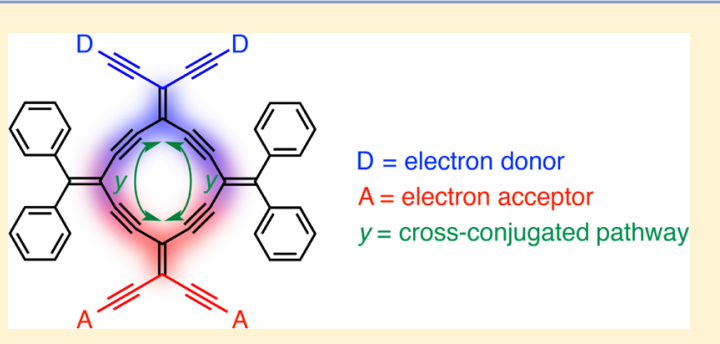
tional theory and time dependent DFT). The combined use of theory and experiment provides a basis to evaluate the extent of $\mathrm{D} / \mathrm{A}$ interactions via the cross-conjugated radialene framework as well as an interpretation of the origin of D/A interactions at an orbital level.

\section{INTRODUCTION}

Conjugated carbon-rich macrocycles are intriguing targets of study for both theoretical and experimental chemists because of their often symmetrical shape and aesthetically appealing structures. They are, however, useful molecules as well, with potential as the organic component for electronic, optical, and nonlinear optical applications. ${ }^{1-8}$ A specific subcategory of conjugated macrocycles are the $[n]$ radialenes, which are cyclic, carbon-rich molecules with a general formula $\mathrm{C}_{2 n} \mathrm{H}_{2 n}$ that contain $n$ ring atoms and $n$ exocyclic double bonds (1, Figure 1). "Expanded



Figure 1. Schematic structure of $[n]$ radialenes and expanded $[n]$ radialenes.

radialenes" are derivatives of radialenes that originate by formal insertion of an unsaturated spacer between each pair of exomethylene fragments of a radialene, giving rise to macrocycles such as 2 and 3 (Figure 1). ${ }^{8-12}$ Work with expanded radialenes was pioneered by Diederich and co-workers ${ }^{13-16}$ via the introduction of diacetylene moieties into the radialene framework to give derivatives with the general structure $3^{17,18}$ as well as structurally related radiannulenes. ${ }^{19-27}$ More recently, expanded radialenes $\mathbf{2}$ composed of repeating enyne units have been realized and studied. ${ }^{28-30}$

The two-dimensionally (2D) conjugated structure of expanded $[n]$ radialenes is rather special because it combines a number of linearly and cross-conjugated pathways placed on a nonbenzoid carbon framework. ${ }^{31-39}$ One key question concerning the properties of expanded $[n]$ radialenes has been the role played by cross-conjugation ${ }^{9,40,41}$ to the overall electronic makeup of these unique molecules. The influence of $\mathrm{D}-\mathrm{A}$ or $\mathrm{D} / \mathrm{A}$ interactions ${ }^{42}$ via cross conjugation in acyclic systems has been explored by a number of groups. ${ }^{9,10,43-46}$ To date, however, only a few examples of donor- or acceptor-expanded radialenes have been reported. ${ }^{18,28}$ Finally, donor-acceptor-expanded radialenes remain unknown, and there have been no attempts to document cross-conjugated interactions in these derivatives using theory.

Our group has recently reported a modular approach for the synthesis of perphenylated expanded $[n]$ radialenes $^{29}$ and radiaannulenes. $^{22,29}$ This approach has been especially useful in

Received: July 17, 2014

Published: September 26, 2014 

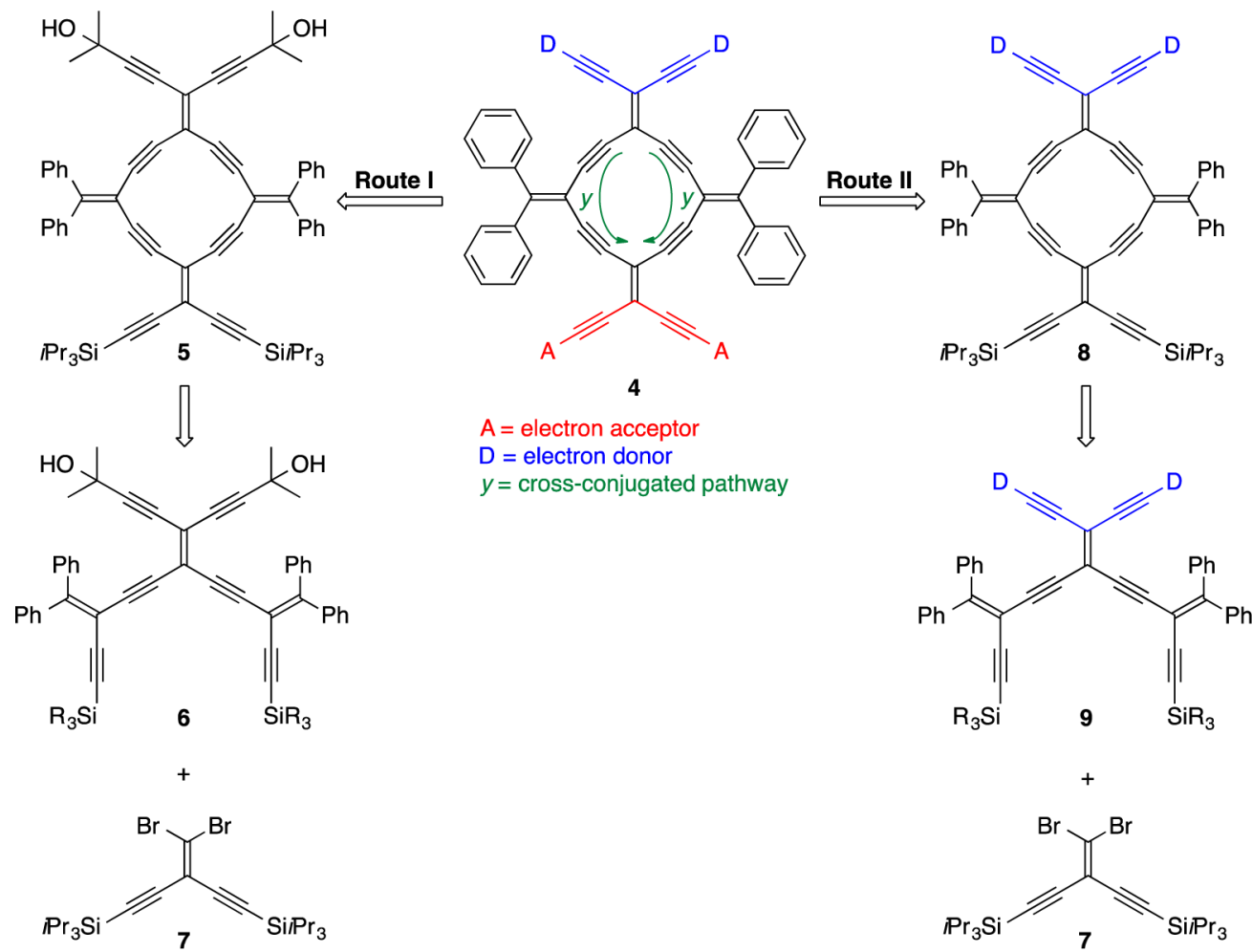

Figure 2. Retrosynthetic analysis of D-A-substituted expanded [4]radialenes.

producing expanded $[4]$ radialenes $^{28,29}$ (i.e., Figure 1, 2 with $m=1$ ) from acyclic iso-polydiacetylene (iso-PDA) precursors, ${ }^{47}$ both in terms of yield and product stability. The successful synthesis of an expanded [4] radialene seemingly comes about through a balance achieved between ring strain present in a smaller expanded [3] radialene and the steric and/or entropic effects that challenge the formation of larger expanded [5]- and [6]radialenes. ${ }^{29}$ With this in mind, expanded [4] radialenes were chosen as the $2 \mathrm{D}$ cross-conjugated framework for incorporating electron donors and acceptors. The results of our synthetic efforts are reported herein, and experimentally obtained electronic absorption and X-ray crystallographic analyses are then compared and explained through the use of quantum chemical computational results using density functional theory (DFT) and time-dependent DFT (TDDFT). This combined effort allows for the evaluation of effects based on incorporation of donor and acceptor groups to the expanded radialene skeleton and communication via cross-conjugation.

\section{RESULTS AND DISCUSSION}

Synthesis. The synthesis of D/A-substituted expanded [4]radialenes 4 was envisioned from two different approaches (Figure 2). The first method, Route I, would seem to offer the greatest potential for product diversity through the incorporation of orthogonal alkyne protecting groups to the framework of radialene 5 . Thus, radialene 5 could be assembled from iso-PDA 6 and dibromoolefin 7, and this would be followed by selective removal of either the acetone or triisopropylsilyl protecting groups to allow for installation of the $\mathrm{D}$ and/or A substituents via a Sonogashira cross coupling ${ }^{48,49}$ with the appropriate aryl halide. An alternative approach (Route II) makes use of expanded radialene $\mathbf{8}$, in which donor functionalities have already been incorporated via the ring-closure reaction of iso-PDA 9 and dibromoolefin 7. The D-A substituted expanded [4]radialenes could then be obtained via desilylation of $\mathbf{8}$ and Sonogashira cross-coupling of the resulting terminal alkyne with the appropriate aryl halide.

Following Route I, the assembly of 5 began with the formation of tetraethynylethene 10 via the Sonogashira cross-coupling reaction of the known dibromoolefin $7^{50}$ with 2-methyl-2-but-3-ynol (Scheme 1). ${ }^{51}$ It is noteworthy that the presence of the two 2-hydroxyprop-2-yl groups ${ }^{52,53}$ is also predicted to help in the chromatographic purification due to the increased polarity of the alcohol functional groups in comparison to the more commonly used trialkylsilyl groups. Selective removal of the triisopropylsilyl

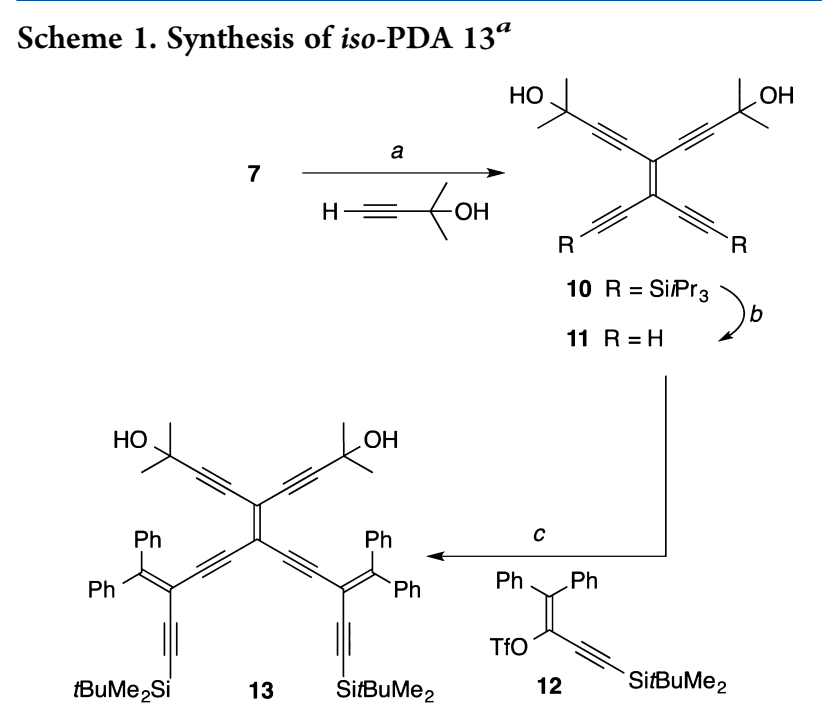

${ }^{a}$ Reagents and conditions: (a) $\mathrm{Pd}\left(\mathrm{PPh}_{3}\right)_{4}, \mathrm{CuI}, \mathrm{Et}_{3} \mathrm{~N}$, THF, reflux, $24 \mathrm{~h}$ (80\%); (b) TBAF, wet THF, $0{ }^{\circ} \mathrm{C}$; (c) 12, $\mathrm{Pd}\left(\mathrm{PPh}_{3}\right)_{4}, \mathrm{CuI}, i \mathrm{Pr}_{2} \mathrm{NH}$, THF, reflux, $24 \mathrm{~h}$ ( $86 \%$ from 10 ). 
Scheme 2. Synthesis of Donor and Acceptor Expanded [4]Radialenes 15-19 ${ }^{a}$

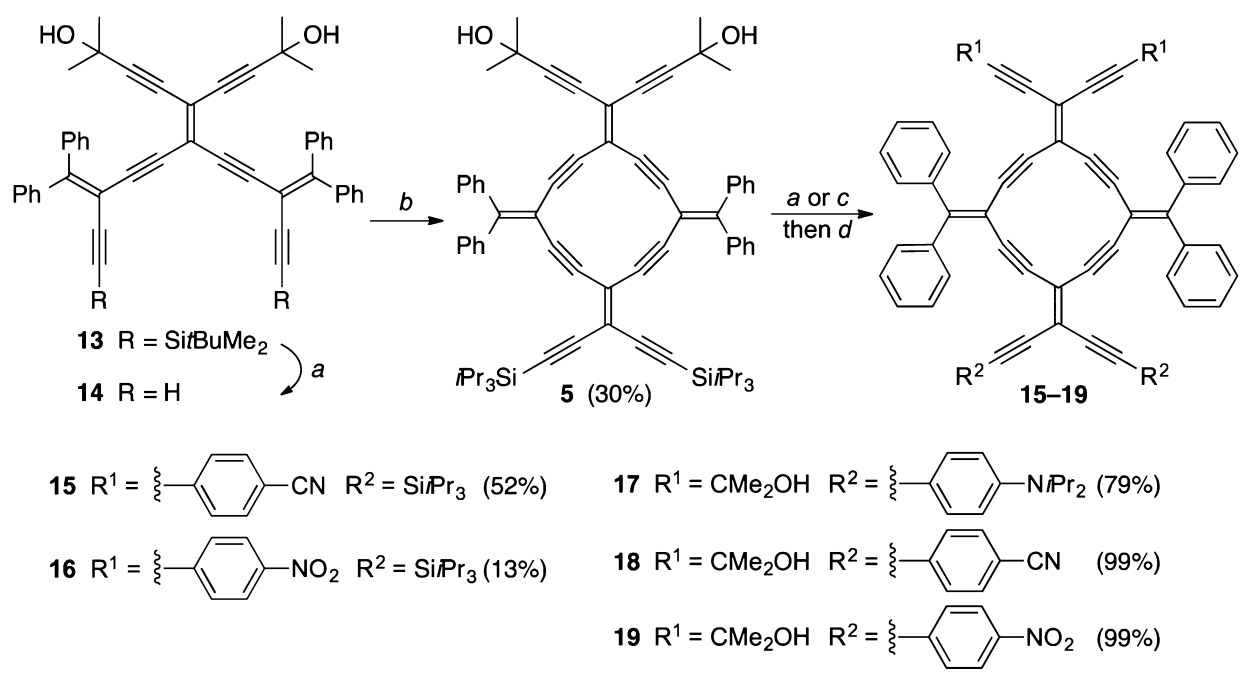

${ }^{a}$ Reagents and conditions: (a) TBAF, wet THF, $0{ }^{\circ} \mathrm{C}$; (b) 7, Pd( $\left.\mathrm{PPh}_{3}\right)_{4}, \mathrm{CuI}, \mathrm{Pr}_{2} \mathrm{NH}$, THF, reflux, $24 \mathrm{~h}$; (c) KOH, $\mathrm{PhH}$, reflux. (d) 4-I-C $\mathrm{H}_{4}-\mathrm{X}$ $\left(\mathrm{X}=\mathrm{NiPr}{ }_{2}, \mathrm{CN}\right.$, or $\left.\mathrm{NO}_{2}\right), \mathrm{Pd}\left(\mathrm{PPh}_{3}\right)_{4}, \mathrm{CuI}, i \mathrm{Pr}_{2} \mathrm{NH}, \mathrm{THF}$, reflux, $15-18 \mathrm{~h}$.

protecting groups in 10 was effected using TBAF in THF at $0{ }^{\circ} \mathrm{C}$ to give the terminal alkyne $\mathbf{1 1}$. With the expectation that $\mathbf{1 1}$ would not be particularly stable to purification, it was carried on following workup to a Sonogashira reaction with vinyl triflate $12^{47}$ to afford orthogonally protected iso-PDA 13 in $86 \%$ isolated yield after column chromatography.

Selective removal of the tert-butyldimethylsilyl groups in isoPDA 13 with TBAF in wet THF at $0{ }^{\circ} \mathrm{C}$ gave 14, which was quickly carried on to a Sonogashira cross-coupling reaction with dibromoolefin 7 (Scheme 2) using conditions reported for the formation of other, analogous expanded [4] radialenes. ${ }^{28,29}$ This cross-coupling reaction gave the orthogonally protected expanded [4] radialene 5 in $30 \%$ yield, and while this macrocyclization reaction was less efficient than hoped, it gave sufficient material for subsequent derivatization.

With the orthogonally protected building block 5 in hand, the introduction of donor and acceptor groups to the crossconjugated framework was explored. Given that the Sonogashira reaction with electron-deficient arenes should progress better than that with electron-rich arenes, the former were used first to establish the methodology. To this end, $\mathbf{5}$ was treated with $\mathrm{KOH}$ in refluxing benzene to remove the 2-hydroxyprop-2-yl protecting groups. As this reaction progressed, however, TLC analysis indicated that liberation of the terminal acetylenes was accompanied by the significant decomposition of the radialene product, as evidenced by the development of significant baseline material. In retrospect, this was probably not completely surprising given the electron-deficient nature of the radialene and the potential instability toward hydroxide at elevated temperature. In spite of the inefficient deprotection, however, the resulting product bearing two terminal alkynes could be pushed forward to a 2 -fold Sonogashira cross-coupling reaction with either $p$-iodobenzonitrile or $p$-iodonitrobenzene. This gave acceptor-substituted expanded [4] radialenes $\mathbf{1 5}$ and $\mathbf{1 6}$ in 52\% and $13 \%$ yield, respectively, as stable solids. Further elaboration of these derivatives was, however, abandoned due to procedural difficulties with this protocol and moderate to low yields of 5 and 15-16.

Although expanded [4] radialene 5 was not deemed a good precursor to form a donor-acceptor radialene, it did provide a valuable precursor for the synthesis of derivatives 17-19, which served as model compounds to explore the effects of stepwise $\mathrm{D} / \mathrm{A}$ substitution of the radialene skeleton. Thus, treatment of 5 with $\mathrm{TBAF}$ in wet $\mathrm{THF}$ at $0{ }^{\circ} \mathrm{C}$ effectively removed the triisopropylsilyl groups without appreciable decomposition. The deprotected radialene was then used in a 2-fold Sonogashira cross-coupling reaction with $p$-iodo- $N, N$-diisopropylaniline, $p$-iodobenzonitrile, or $p$-iodonitrobenzene to give 17-19, respectively. Following column chromatography, the D/Aexpanded [4] radialenes 17-19 were isolated in good to excellent yield as air-stable solids with decomposition points in the range of $180-230^{\circ} \mathrm{C}$ as measured by differential scanning calorimetry (DSC).

In view of the difficulties encountered with the removal of the 2-hydroxypropyl protecting groups from $\mathbf{5}$, the alternative route to donor-acceptor radialenes was pursued i.e., incorporation of the donor moieties at the initial stage of the synthesis (Figure 1, Route II). Starting with tetraethynylethene $\mathbf{2 0}$ (Scheme 3), protodesilylation with $\mathrm{K}_{2} \mathrm{CO}_{3}$ in $\mathrm{MeOH} / \mathrm{THF}$ removed the trimethylsilyl groups to give $\mathbf{2 1}$, which was used directly in a 2 -fold Sonogashira cross-coupling reaction with vinyl triflate $12^{47}$ to give iso-PDA 22 in $76 \%$ isolated yield. Removal of the two tertbutyldimethylsilyl groups of compound 22 in the usual way using TBAF liberated the terminal alkynes, and this desilylated product was carried on to a Sonogashira cross-coupling reaction with dibromoolefin 7 to give the desired radialene $\mathbf{2 3}$ as a red solid in $27 \%$ isolated yield. While the yield of $\mathbf{2 3}$ was modest, purification was reasonably straightforward using a sequence of column chromatography and recrystallization from $\mathrm{CH}_{2} \mathrm{Cl}_{2}$. Gratifyingly desilylation of $\mathbf{2 3}$ proceeded smoothly in the presence of TBAF, with little or no evidence of decomposition based on TLC analysis. Following desilylation and workup, the product was carried on directly to a Sonogashira cross-coupling reaction with 4-iodo$\mathrm{N}, \mathrm{N}$-diisopropylaniline to give the donor-substituted expanded [4] radialene $\mathbf{2 4}$ in a reasonable isolated yield of $40 \%$ yield. An analogous sequence starting with 23 also generated the $\mathrm{D}-\mathrm{A}$ expanded [4] radialenes $\mathbf{2 5}$ and $\mathbf{2 6}$ in acceptable yield. DSC analysis confirmed that functionalized [4] radialenes 23-26, with decomposition points in the range of $240-300{ }^{\circ} \mathrm{C}$, showed stability similar to that of 17-19. Thus, it seemed clear at this point that the latter synthetic pathway, Route II, as outlined in 
Scheme 3. Synthesis of Donor and/or Donor-Acceptor Expanded [4]Radialenes 23-26 ${ }^{a}$
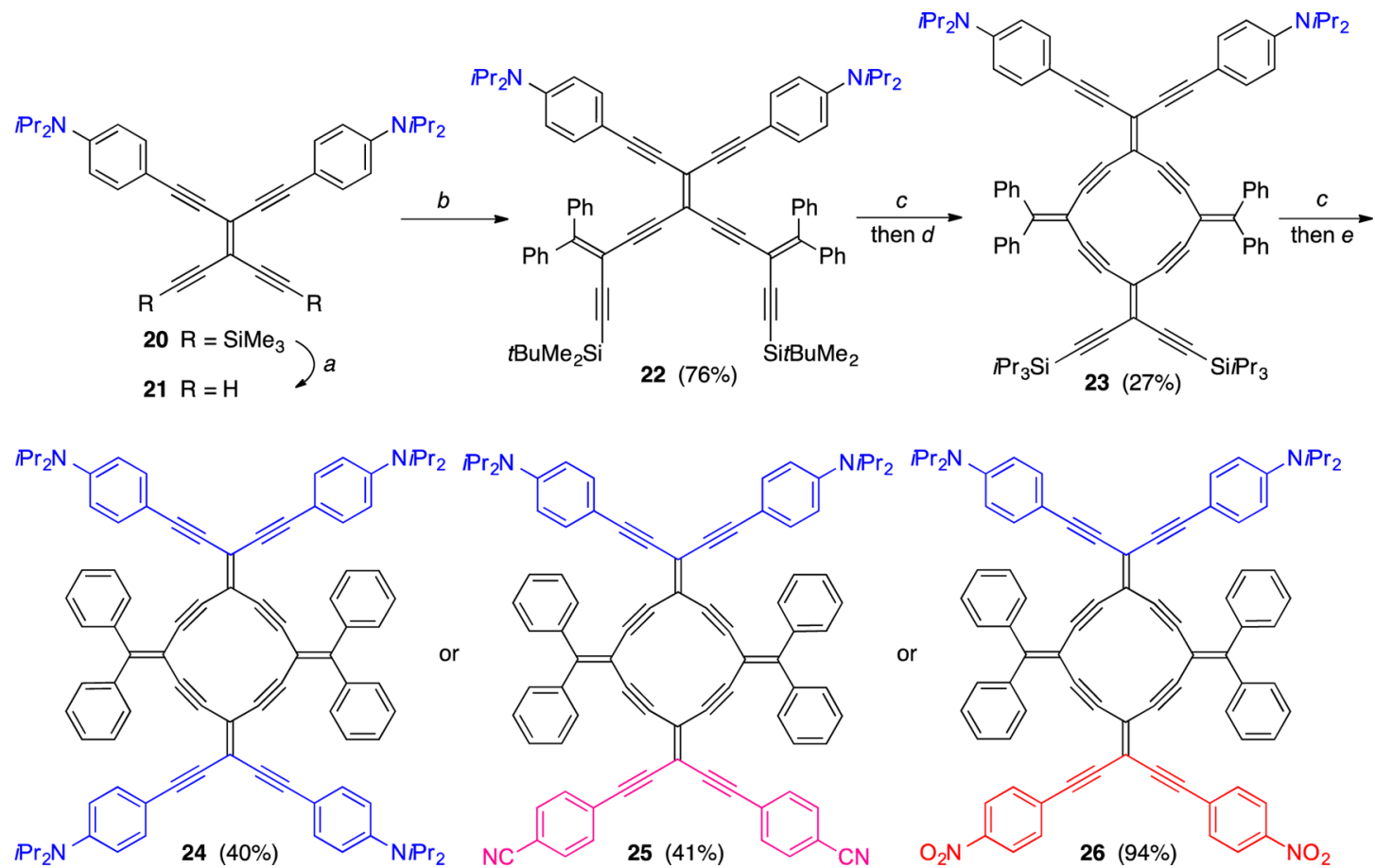

${ }^{a}$ Reagents and conditions: (a) $\mathrm{K}_{2} \mathrm{CO}_{3}$, THF/MeOH, rt; (b) 12, $\mathrm{Pd}\left(\mathrm{PPh}_{3}\right)_{4}, \mathrm{CuI}, i \mathrm{Pr}_{2} \mathrm{NH}, \mathrm{THF}$, reflux, $24 \mathrm{~h}$; (c) TBAF, wet THF, $0{ }^{\circ} \mathrm{C}$; $(\mathrm{d}) 7$, $\mathrm{Pd}\left(\mathrm{PPh}_{3}\right)_{4}, \mathrm{CuI}, i \mathrm{Pr}_{2} \mathrm{NH}$, THF, reflux, $24 \mathrm{~h}$; (e) $\mathrm{I}-\mathrm{C}_{6} \mathrm{H}_{4}-\mathrm{X}\left(\mathrm{X}=\mathrm{NiPr}, \mathrm{CN}\right.$, or $\left.\mathrm{NO}_{2}\right), \mathrm{Pd}\left(\mathrm{PPh}_{3}\right)_{4}, \mathrm{CuI}, \mathrm{Pr}_{2} \mathrm{NH}, \mathrm{THF}, 40-50{ }^{\circ} \mathrm{C}, 15-18 \mathrm{~h}$.

(a)

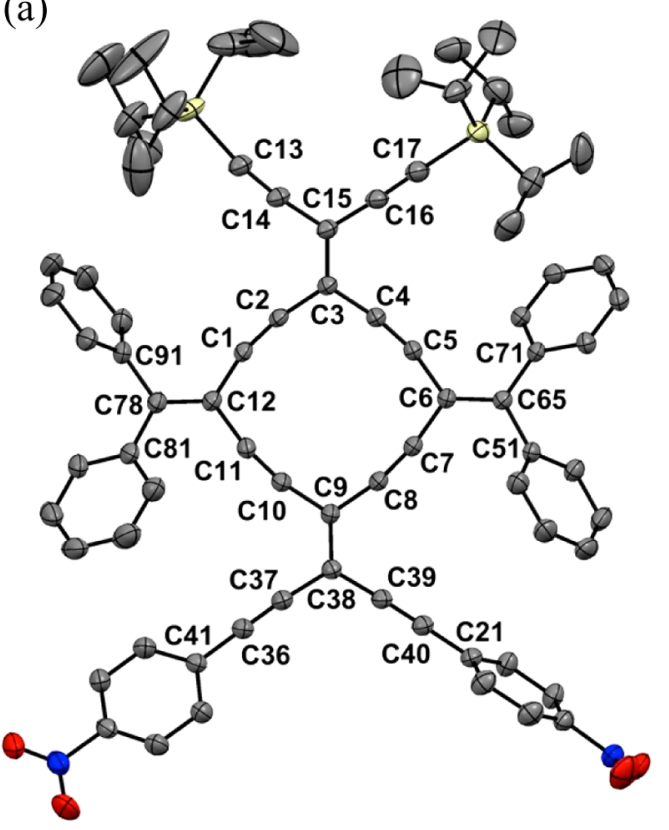

(c)

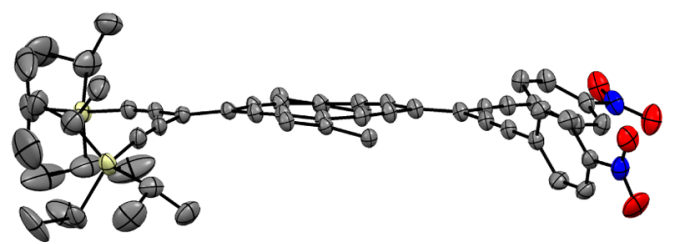

(b)
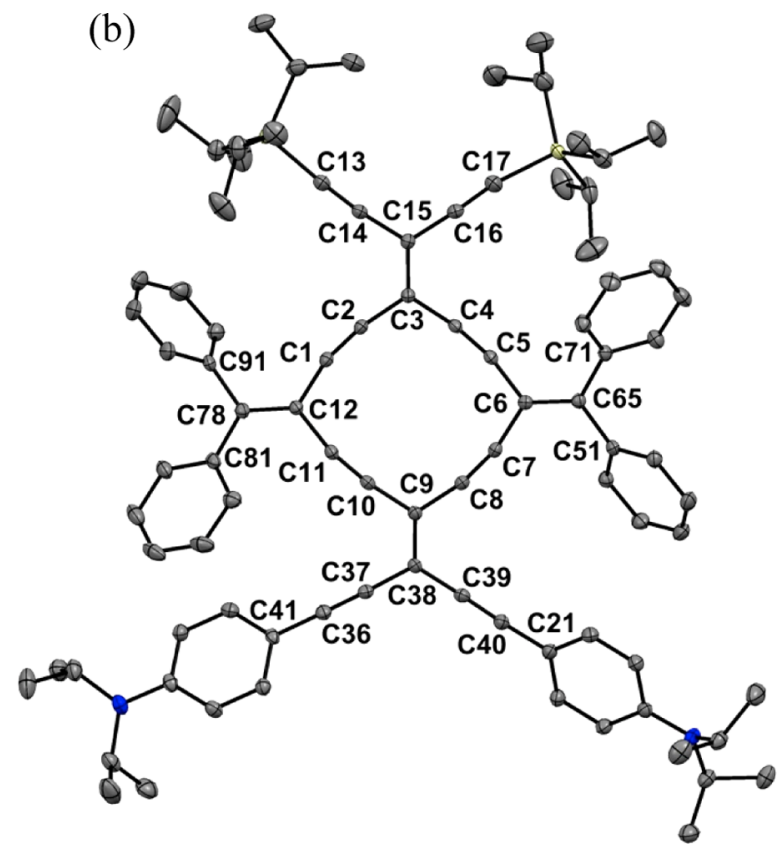

(d)

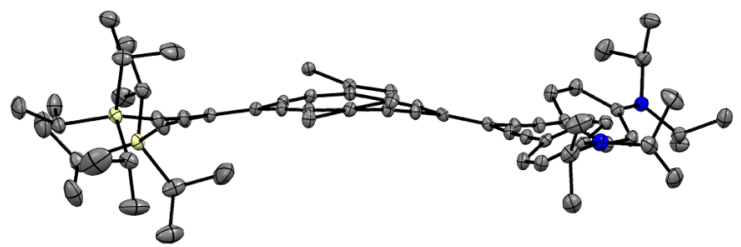

Figure 3. ORTEP drawings 16 and 23. (a, b) Top-down view of 16 and 23, respectively. (c, d) Side-on view of 16 and 23, respectively. ORTEPs drawn at $30 \%$ level. $\mathrm{H}$ atoms and cocrystallized solvent removed for clarity; only ipso-carbon of alkylidene phenyl rings are shown in (c) and (d). 
Table 1. Selected X-ray (Black) and Computed (Red) Bond Lengths and Angles for the Expanded [4]Radialenes 16 and 23

\begin{tabular}{|c|c|c|c|c|c|}
\hline \multirow[t]{2}{*}{ Bond } & \multicolumn{2}{|c|}{ Length $[\AA]$} & \multirow[t]{2}{*}{ Atoms } & \multicolumn{2}{|l|}{ Angle $\left[^{\circ}\right]$} \\
\hline & 16 & 23 & & 16 & 23 \\
\hline \multirow[t]{2}{*}{$\mathrm{C} 12-\mathrm{C} 1$} & $1.440(5)$ & $1.439(2)$ & $\mathrm{C} 12-\mathrm{C} 1-\mathrm{C} 2$ & $166.3(3)$ & $165.49(17)$ \\
\hline & 1.4317 & 1.4325 & & 168.89 & 169.09 \\
\hline \multirow[t]{2}{*}{$\mathrm{C} 1-\mathrm{C} 2$} & $1.202(5)$ & $1.200(2)$ & $\mathrm{C} 1-\mathrm{C} 2-\mathrm{C} 3$ & $169.5(3)$ & $170.10(17)$ \\
\hline & 1.2093 & 1.2094 & & 170.07 & 169.97 \\
\hline \multirow[t]{2}{*}{$\mathrm{C} 2-\mathrm{C} 3$} & $1.433(5)$ & $1.429(2)$ & $\mathrm{C} 2-\mathrm{C} 3-\mathrm{C} 4$ & $113.5(3)$ & $113.42(14)$ \\
\hline & 1.4236 & 1.4234 & & 112.48 & 112.56 \\
\hline \multirow[t]{2}{*}{ C3-C4 } & $1.424(5)$ & $1.429(2)$ & $\mathrm{C} 3-\mathrm{C} 4-\mathrm{C} 5$ & 171.2(3) & $171.40(17)$ \\
\hline & 1.4236 & 1.4235 & & 170.07 & 169.95 \\
\hline \multirow[t]{2}{*}{$\mathrm{C} 4-\mathrm{C} 5$} & $1.212(5)$ & $1.202(2)$ & C4-C5-C6 & $165.9(3)$ & $167.38(17)$ \\
\hline & 1.2093 & 1.2094 & & 168.89 & 169.05 \\
\hline \multirow[t]{2}{*}{$\mathrm{C} 5-\mathrm{C} 6$} & $1.443(5)$ & $1.437(2)$ & $\mathrm{C} 5-\mathrm{C} 6-\mathrm{C} 7$ & $110.0(3)$ & $109.73(14)$ \\
\hline & 1.4317 & 1.4325 & & 109.69 & 109.68 \\
\hline \multirow[t]{2}{*}{ C6-C7 } & $1.428(5)$ & $1.443(2)$ & C6-C7-C8 & $170.4(3)$ & $167.26(17)$ \\
\hline & 1.4329 & 1.4325 & & 166.93 & 167.01 \\
\hline \multirow[t]{2}{*}{$\mathrm{C} 7-\mathrm{C} 8$} & $1.209(5)$ & $1.200(2)$ & $\mathrm{C} 7-\mathrm{C} 8-\mathrm{C} 9$ & $168.8(3)$ & $168.30(17)$ \\
\hline & 1.2110 & 1.2111 & & 170.34 & 170.62 \\
\hline \multirow[t]{2}{*}{ C8-C9 } & $1.429(5)$ & $1.430(2)$ & $\mathrm{C} 8-\mathrm{C} 9-\mathrm{C} 10$ & $112.6(3)$ & $113.15(14)$ \\
\hline & 1.4228 & 1.4240 & & 113.01 & 112.90 \\
\hline \multirow[t]{2}{*}{ C9-C10 } & $1.422(5)$ & $1.426(2)$ & C9-C10-C11 & $168.5(3)$ & $172.50(17)$ \\
\hline & 1.4228 & 1.4240 & & 170.34 & 170.58 \\
\hline \multirow[t]{2}{*}{$\mathrm{C} 10-\mathrm{C} 11$} & $1.200(5)$ & $1.202(2)$ & $\mathrm{C} 10-\mathrm{C} 11-\mathrm{C} 12$ & $170.1(4)$ & $167.96(17)$ \\
\hline & 1.2111 & 1.2111 & & 166.93 & 166.95 \\
\hline \multirow[t]{2}{*}{$\mathrm{C} 11-\mathrm{C} 12$} & $1.433(5)$ & $1.436(2)$ & $\mathrm{C} 11-\mathrm{C} 12-\mathrm{C} 1$ & $110.7(3)$ & $109.49(13)$ \\
\hline & 1.4329 & 1.4326 & & 109.69 & 109.68 \\
\hline \multirow[t]{2}{*}{ C9-C38 } & $1.369(5)$ & $1.375(2)$ & $\mathrm{C} 14-\mathrm{C} 15-\mathrm{C} 16$ & $115.6(3)$ & $115.90(14)$ \\
\hline & 1.3745 & 1.3754 & & 118.32 & 118.34 \\
\hline \multirow[t]{2}{*}{ C $37-\mathrm{C} 38$} & $1.430(5)$ & $1.425(2)$ & C37-C $38-\mathrm{C} 39$ & $116.9(3)$ & $118.47(14)$ \\
\hline & 1.4199 & 1.4189 & & 118.09 & 117.33 \\
\hline \multirow[t]{2}{*}{ C36-C37 } & $1.196(5)$ & $1.197(2)$ & C51-C65-C71 & $117.8(3)$ & $116.40(14)$ \\
\hline & 1.2088 & 1.2105 & & 117.24 & 117.19 \\
\hline \multirow[t]{2}{*}{ C36-C41 } & $1.428(5)$ & $1.428(2)$ & C81-C78-C91 & $116.8(3)$ & $116.24(14)$ \\
\hline & 1.4241 & 1.4219 & & 117.24 & 117.20 \\
\hline \multirow[t]{2}{*}{ C38-C39 } & $1.424(5)$ & $1.414(2)$ & & & \\
\hline & 1.4199 & 1.4188 & & & \\
\hline \multirow[t]{2}{*}{ C39-C40 } & $1.197(5)$ & $1.206(2)$ & & & \\
\hline & 1.2088 & 1.2105 & & & \\
\hline \multirow[t]{2}{*}{$\mathrm{C} 40-\mathrm{C} 21$} & $1.437(5)$ & $1.424(2)$ & & & \\
\hline & 1.4241 & 1.4220 & & & \\
\hline
\end{tabular}

Scheme 3 offered the more efficient and reasonably versatile route to D-A-expanded [4]radialenes.

Whereas removal of the acetone protecting groups from expanded [4] radialene 5 proved difficult (vide supra), selective removal of this protecting group from iso-PDA 13 in the presence of the tert-butyldimethylsilyl group was quite successful for preparing acyclic model compounds, iso-PDAs 27 and 28 (eq 1). Thus, treatment of iso-PDA 13 with $\mathrm{KOH}$ in benzene gave the terminal alkynes, and, following workup, the crude product was carried on to the Sonogashira reaction with either 4-iodobenzonitrile or 4-iodonitrobenzene to give acceptor-containing iso-PDAs $\mathbf{2 7}$ and $\mathbf{2 8}$ in 57\% and 59\% isolated yield, respectively, over the two steps from 13.

13

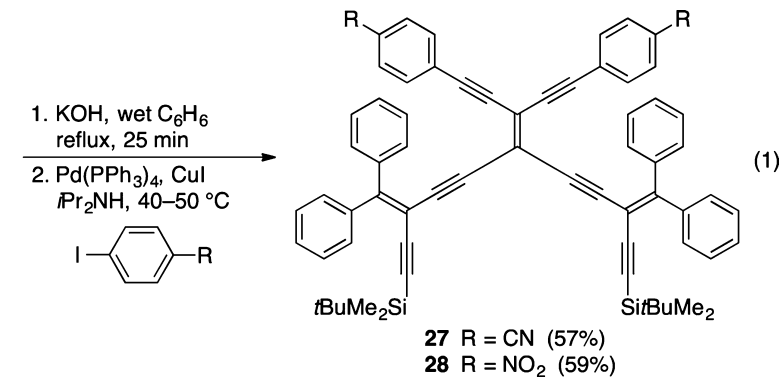

X-ray Crystallography. Crystals of acceptor-substituted expanded [4] radialene $\mathbf{1 6}$ have been grown by slow evaporation of $\mathrm{CH}_{2} \mathrm{Cl}_{2}$ solution. Conversely, crystals of donor-substituted expanded [4] radialene $\mathbf{2 3}$ suitable for X-ray crystallography have been grown from a $\mathrm{CH}_{2} \mathrm{Cl}_{2}$ solution that had been layered with hexanes and refrigerated at $4{ }^{\circ} \mathrm{C}$. ORTEP drawings for both molecules are shown in Figure 3 from both a top-down and side-on perspective. In general, both molecules show a similar overall conformation, with a slight "cupping" of the conjugated framework that is best appreciated from the side-on views in Figure 3c,d.

From the top-down view, it is clear that the bond angles at the carbon atoms of the acetylene bonds of the cross-conjugated enyne skeleton deviate from the linear value of $180^{\circ}$. Krebs, in his review on strained cycloalkynes, regarded acetylenic bond angles less than $170^{\circ}$ as being strained. ${ }^{54}$ Radialenes 16 and 23 are thus "strained" macrocycles, such that the crystal structure of 23 shows acetylenic bond angles within the macrocyclic core that range from $165.5(17)^{\circ}$ to $172.5(17)^{\circ}$ (see Table 1 ), while the analogous bond angles for 16 span a range from $165.9(3)^{\circ}$ to $171.2(3)^{\circ}$, in line with other expanded [4] radialenes reported to date. $^{28,29}$ The endocyclic alkylidene bond angles based on the TEE fragments of $\mathbf{1 6}$ and $\mathbf{2 3}$ (C2-C3-C4 and C8-C9-C10) all fall in a narrow range of $112.6^{\circ}$ to $113.5^{\circ}$. These values also reflect the ring strain in $\mathbf{1 6}$ and $\mathbf{2 3}$, as the bond angles are somewhat smaller than values of $115-120^{\circ}$ found for TEE units in acyclic molecules. ${ }^{18,55}$ The endocyclic alkylidene angles of the two gem-diethynylethene (DEE) segments of 16 and 23 
Table 2. Experimental $\left(\lambda_{\text {exp }}\right)$ and Computational $\left(\lambda_{\text {com }}\right)$ UV-vis Absorption and Experimental Emission Data $\left(\lambda_{\text {em }}\right)$ for iso-PDAs and Expanded [4] Radialenes ${ }^{a}$

\begin{tabular}{llll}
\hline cmpd & $\lambda_{\exp }(\varepsilon) / \mathrm{nm}\left(\mathrm{L} \mathrm{mol}^{-1} \mathrm{~cm}^{-1}\right)$ & $\lambda_{\text {em }}$ & Stokes \\
& $\lambda_{\text {com }} /(f) \mathrm{nm}$ composition & $/ \mathrm{nm}^{b}$ & shift \\
& & $/ \mathrm{nm}(\mathrm{eV})$
\end{tabular}

\begin{tabular}{|c|c|c|c|c|c|}
\hline \multicolumn{6}{|c|}{ iso-polydiacetylenes (iso-PDAs) } \\
\hline 13 & $255(37800)$ & $319(26400)$ & $395(28400)$ & $e$ & \\
\hline $13^{\prime}$ & $280(0.26) \mathrm{H}-1 ; \mathrm{L}+1, \mathrm{H}-2 ; \mathrm{L}$ & $353(1.25) \mathrm{H}-1 ; \mathrm{L}$ & $391(0.17) \mathrm{H} ; \mathrm{L}$ & & \\
\hline 22 & $318(49200)$ & $388(22700)$ & $475(47300)$ & 609 & $134(0.57)$ \\
\hline $22^{\prime}$ & $\begin{array}{l}303(0.28) \mathrm{H}-3 ; \mathrm{L} \\
262(0.54) \mathrm{H} ; \mathrm{L}+3\end{array}$ & $\begin{array}{l}358(1.81) \\
\mathrm{H}-2 ; \mathrm{L}, \mathrm{H}-1 ; \mathrm{L}, \mathrm{H} ; \mathrm{L}+1\end{array}$ & $468(0.64) \mathrm{H} ; \mathrm{L}$ & & \\
\hline 27 & $250(49600)$ & $332(63400)$ & $448(30900)$ & 538 & $90(0.46)$ \\
\hline $27^{\prime}$ & $259(0.18) \mathrm{H}-7 ; \mathrm{L}$ & $310(1.53) \mathrm{H}-3 ; \mathrm{L}$ & $455(0.58) \mathrm{H} ; \mathrm{L}$ & & \\
\hline 28 & $249(39500)$ & $327(42600)$ & $459(27300)$ & 566 & $107(0.51)$ \\
\hline $28^{\prime}$ & $293(0.22) \mathrm{H}-3 ; \mathrm{L}$ & $329(1.05) \mathrm{H} ; \mathrm{L}+1$ & $461(0.57) \mathrm{H} ; \mathrm{L}$ & & \\
\hline \multicolumn{6}{|c|}{ expanded[4]radialenes } \\
\hline 5 & $275(31000)$ & $393(127800)$ & $436(\mathrm{sh}, 29900)$ & $e$ & \\
\hline $5^{\prime}$ & $267(0.10) \mathrm{H}-7 ; \mathrm{L}$ & $\begin{array}{l}379(1.26) \mathrm{H}-1 ; \mathrm{L} \\
357(1.18) \mathrm{H}-2 ; \mathrm{L}, \mathrm{H} ; \mathrm{L}+1\end{array}$ & $417(0.00) \mathrm{H} ; \mathrm{L}$ & & \\
\hline 15 & $339(27400)$ & $414(63900)$ & $d$ & $c$ & \\
\hline $15^{\prime}$ & $310(1.58) \mathrm{H}-3 ; \mathrm{L}, \mathrm{H} ; \mathrm{L}+3$ & $\begin{array}{l}383(1.04) \mathrm{H}-1 ; \mathrm{L}, \mathrm{H} ; \mathrm{L}+1 \\
390(0.95) \mathrm{H}-2 ; \mathrm{L}\end{array}$ & $471(0.45) \mathrm{H} ; \mathrm{L}$ & & \\
\hline 16 & $c$ & & & $c$ & \\
\hline $16^{\prime}$ & $\begin{array}{l}330(0.74) \mathrm{H} ; \mathrm{L}+2 \\
295(0.26) \mathrm{H}-4 ; \mathrm{L}\end{array}$ & $\begin{array}{l}395(0.83) \mathrm{H}-1 ; \mathrm{L} \\
385(0.98) \mathrm{H}-2 ; \mathrm{L}, \mathrm{H} ; \mathrm{L}+1\end{array}$ & $477(0.45) \mathrm{H} ; \mathrm{L}$ & & \\
\hline 17 & $403(70400)$ & $486(29000)$ & $550(24300)$ & 659 & $109(0.37)$ \\
\hline $17^{\prime}$ & $\begin{array}{l}368(1.90) \mathrm{H}-1 ; \mathrm{L} \\
397(1.25) \mathrm{H}-2 ; \mathrm{L}\end{array}$ & - & $484(0.52) \mathrm{H} ; \mathrm{L}$ & & \\
\hline 18 & $409(93800)$ & - & $482(\mathrm{sh}, 14800)$ & 574 & $92(0.41)$ \\
\hline $18^{\prime}$ & $398(1.26) \mathrm{H}-1 ; \mathrm{L}, \mathrm{H} ; \mathrm{L}+1$ & - & $478(0.33) \mathrm{H} ; \mathrm{L}$ & & \\
\hline 19 & $277(33000)$ & $412(77000)$ & $500(\mathrm{sh}, 12900)$ & 595 & $95(0.40)$ \\
\hline $19^{\prime}$ & $293(0.16) \mathrm{H}-1 ; \mathrm{L}+3$ & $\begin{array}{l}401(1.19) \mathrm{H}-1 ; \mathrm{L}, \mathrm{H} ; \mathrm{L}+1 \\
394(0.80) \mathrm{H}-2 ; \mathrm{L}\end{array}$ & $485(0.34) \mathrm{H} ; \mathrm{L}$ & & \\
\hline 23 & $388(76400)$ & $485(\mathrm{sh}, 32200)$ & $544(\mathrm{sh}, 24300)$ & 656 & $116(0.39)$ \\
\hline $23^{\prime}$ & $\begin{array}{l}370(1.61) \mathrm{H}-1 ; \mathrm{L} \\
387(1.09) \mathrm{H} ; \mathrm{L}+1, \mathrm{H}-2 ; \mathrm{L}\end{array}$ & - & $487(0.5) \mathrm{H} ; \mathrm{L}$ & & \\
\hline 24 & $410(81500)$ & $492(75400)$ & $535(\mathrm{sh}, 62000)$ & 650 & $115(0.41)$ \\
\hline $24^{\prime}$ & $365(2.23) \mathrm{H}-2 ; \mathrm{L}$ & $459(2.18) \mathrm{H}-1 ; \mathrm{L}+1$ & $495(0.0) \mathrm{H} ; \mathrm{L}$ & & \\
\hline 25 & $403(69900)$ & $485(64600)$ & $573(\mathrm{sh}, 15000)$ & $e$ & \\
\hline $25^{\prime}$ & $384(0.86) \mathrm{H}-1 ; \mathrm{L}, \mathrm{H}-1 ; \mathrm{L}+1$ & $452(2.05) \mathrm{H}-2 ; \mathrm{L}, \mathrm{H} ; \mathrm{L}+1$ & $511(0.04) \mathrm{H} ; \mathrm{L}$ & & \\
\hline 26 & $404(67600)$ & $497(61300)$ & $582(\mathrm{sh}, 12000)$ & $e$ & \\
\hline $26^{\prime}$ & $401(0.52) \mathrm{H}-3 ; \mathrm{L}$ & 457 (2.03) H-2;L, H;L+1 & $519(0.01) \mathrm{H} ; \mathrm{L}$ & & \\
\hline $29^{f f}$ & $\begin{array}{l}400(0.82) \mathrm{H}-2 ; \mathrm{L}(0.6) \\
325(1.16) \mathrm{H} ; \mathrm{L}+4\end{array}$ & $451(1.85) \mathrm{H} ; \mathrm{L}+1, \mathrm{H}-1 ; \mathrm{L}$ & $495(0.00) \mathrm{H} ; \mathrm{L}$ & & \\
\hline
\end{tabular}

${ }^{a} \mathrm{H}=$ HOMO, L = LUMO, $f=$ oscillator strength; experimental absorption and emission data measured in $\mathrm{CH}_{2} \mathrm{Cl}_{2} \cdot{ }^{b} \mathrm{Excitation}$ at $425 \mathrm{~nm} .{ }^{c} \mathrm{Not}$ measured. ${ }^{d}$ A shoulder absorption is evident for 15 (as observed for 18), but it is not possible to accurately estimate a maximum for this signal. ${ }^{e}$ No significant observed emission. ${ }^{f}$ Compound has not been synthesized, thus experimental data is not available.

(C5-C6-C7 and $\mathrm{C} 11-\mathrm{C} 12-\mathrm{C} 1$ ) span a range from $109.5^{\circ}$ to $110.7^{\circ}$, and this is again slightly smaller than similar angles of ca. $113-115^{\circ}$ typically found in acyclic molecules. ${ }^{47}$ The side view of both 16 and 23 shows that the conjugated structures are both slightly curved. The nitrophenyl groups of $\mathbf{1 6}$ are rotated out of planarity by ca. 68 and $31^{\circ}$, while those of the $N, N$-diisopropylaniline rings are twisted by $30^{\circ}$ and $36^{\circ}$ relative to the radialene framework. Thus, in both cases $\pi$-electron communication is diminished between the conjugated framework of the radialene and the donor and acceptor groups in the solid state.

UV-vis Absorption Spectroscopy. The absorption spectra of selected radialenes and iso-PDA model compounds have been measured in dichloromethane at room temperature, and the results are summarized in Table 2. In principle, two main questions come to mind with respect to the absorption spectra of these compounds. (1) What is the influence of the crossconjugated macrocyclic framework in comparison to that of the acyclic diacetylene (iso-PDA), and (2) are donor-acceptor interactions mediated through the macrocyclic framework? The answer to both of these questions, to some extent, can potentially be answered by considering if the lowest energy absorption(s) of a $\mathrm{D}-\mathrm{A}$ radialene are dominated by the longest linearly conjugated segment(s), as would be expected in the absence of a significant contribution from cross-conjugation (Figure 4).

One way to empirically address the first question is to examine whether the electronic make up of the expanded [4] radialenes is greater than the sum of its parts, i.e., is the radialene spectrum simply a summation of contributions from the contributing isoPDA segments? The lowest energy $\lambda_{\max }$ of iso-PDA 22 appears at $475 \mathrm{~nm}$, with evidence of a shoulder at ca. $500 \mathrm{~nm}$ (Figure 5a). Donor radialenes 17 and 23, on the other hand, each show a low energy shoulder absorption ( 550 and $544 \mathrm{~nm}$, respectively), with similar molar absorptivities. Thus, in comparison to acyclic 22, radialenes 17 and 23 clearly show electronic absorptions that cannot be explained through consideration of the longest linearly conjugated segments of $\mathbf{2 2}$ (see Figure 4). Fully substituted "bisdonor" radialene $\mathbf{2 4}$ incorporates aniline groups in both the "North" and "South" positions and shows a strong low energy absorption at $492 \mathrm{~nm}$ that merges with a shoulder absorption at $535 \mathrm{~nm}$. These absorptions correlate well with those of 


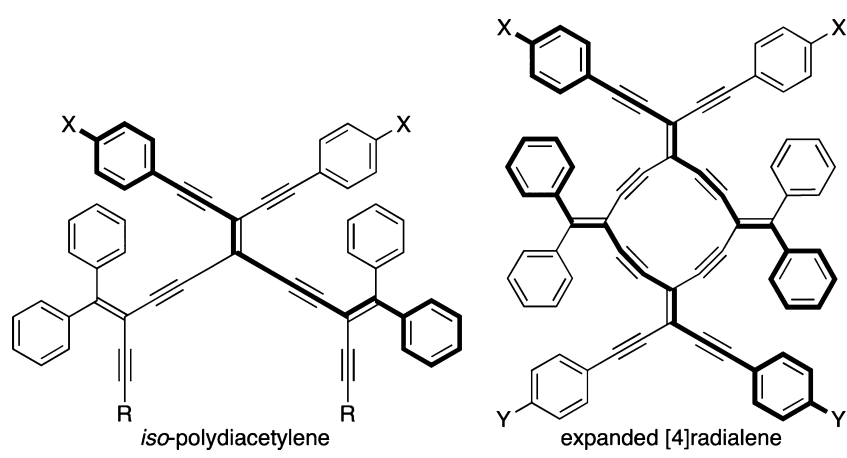

Figure 4. Schematic representation of the longest linearly conjugated segment of iso-PDAs and D/A expanded [4] radialenes (shown in bold).

"mono-donor" 17 and 23, although the absorption intensity is significantly greater for $\mathbf{2 4}$. It is interesting to note that the lowest energy absorption for $\mathbf{2 4}$ is actually slightly blue-shifted relative to 17 and 23 , although the difference is not particularly significant. ${ }^{56}$

The electronic absorption spectrum of $\mathrm{D}-\mathrm{A}$ radialene $\mathbf{2 6}$ also differs quite significantly from that of its subunits, namely donor and acceptor iso-PDAs 22 and 28, respectively (Figure 5b). Most significantly, a low energy shoulder absorption is observed for $\mathbf{2 6}$ at $582 \mathrm{~nm}$, while 22 and 28 show absorptions only at 475 and $459 \mathrm{~nm}$, respectively. An analogous comparison of the spectrum of $\mathrm{D}-\mathrm{A}$ substituted 25 to its constituents parts, i.e., donorsubstituted iso-PDA 22 and acceptor-substituted iso-PDA 27, also reveals a lower energy shoulder absorption at $573 \mathrm{~nm}$ in the spectrum of $\mathbf{2 5}$ that is notably absent in either iso-PDA (see Figure S3). Gratifyingly, the red-shifted absorption characteristics found for the cyclized structures can be explained computationally, as will be discussed below.

An analysis similar to that just described above can be used to examine the impact of $\mathrm{D}-\mathrm{A}$ substitution to the radialene framework (Figure 6a). Thus, a comparison of the spectrum of D-A-substituted 26 to that of donor-substituted 17 and acceptor-substituted 19 reveals that the lowest energy $\lambda_{\max }$ of 26 (a shoulder absorption at $582 \mathrm{~m}$ ) occurs at the lowest energy.
Similarly, a comparison of the spectrum of cyano-substituted D-A-substituted radialene 25 to that of donor-substituted 17 and acceptor-substituted 18 shows that $\lambda_{\max }$ of $\mathbf{2 5}$ (a shoulder absorption at $573 \mathrm{~nm}$ ) also falls at the lowest energy (see Figure S4, Supporting Information). Thus, the $\lambda_{\max }$ of $\mathbf{2 6}$ (and 25) is indeed found at slightly lower energy than that of the radialenes that contain either of the donor or acceptor "parts", but the intensity of the lowest energy shoulder absorption is noticeably lower that that of donor substituted 17. The weakness of the $\lambda_{\max }$ absorption for $\mathbf{2 5}$ and $\mathbf{2 6}$ appears to result from a minimal oscillator strength of the HOMO $\rightarrow$ LUMO transition, as suggested by calculations (vide infra). ${ }^{57}$

Finally, a comparison of the three expanded [4]radialenes 24-26 shows that all three feature a total of three major absorptions, centered at ca. 300, 400, and $500 \mathrm{~nm}$ (Figure 6b). Furthermore, each macrocycle shows a lower energy shoulder absorption. It is worth noting that the energy of the lowest energy absorption for the two D-A substituted expanded [4] radialenes 25 and 26 (at 573 and $582 \mathrm{~nm}$, respectively) is very similar in energy, likely originating from donor-acceptor interaction (vide infra). Conversely, the low energy absorption for $24(492 \mathrm{~nm})$ merges with the shoulder at $535 \mathrm{~nm}$ to give a far more intense absorption than either $\mathbf{2 5}$ or $\mathbf{2 6}$.

To complement the absorption spectra, emission spectra have been measured in deoxygenated $\mathrm{CH}_{2} \mathrm{Cl}_{2}$ with an excitation wavelength of $425 \mathrm{~nm}$ (Table 2 and selected spectra in Figure S5, Supporting Information). ${ }^{58}$ In general, each compound shows a single broad emission peak. There is not a large variance in the associated Stokes shifts that range from 90 to $134 \mathrm{~nm}$ (0.37$0.57 \mathrm{eV}$ ), although the values of the iso-PDAs are slightly higher that those of the radialenes, probably as a result of structural rigidification upon macrocyclization. The incorporation of both donor and acceptor moieties to give $\mathrm{D}-\mathrm{A}$ radialenes $\mathbf{2 5}$ and $\mathbf{2 6}$ results in quenching of the fluorescence, as has been observed for other acetylenic scaffolds containing donor and acceptor substituents. ${ }^{59,60}$ Thus, the fluorescence quenching in 25 and 26 is consistent with $\mathrm{D}-\mathrm{A}$ communication in these macrocycles, but certainly does not constitute proof of a $\mathrm{D}-\mathrm{A}$ interaction.
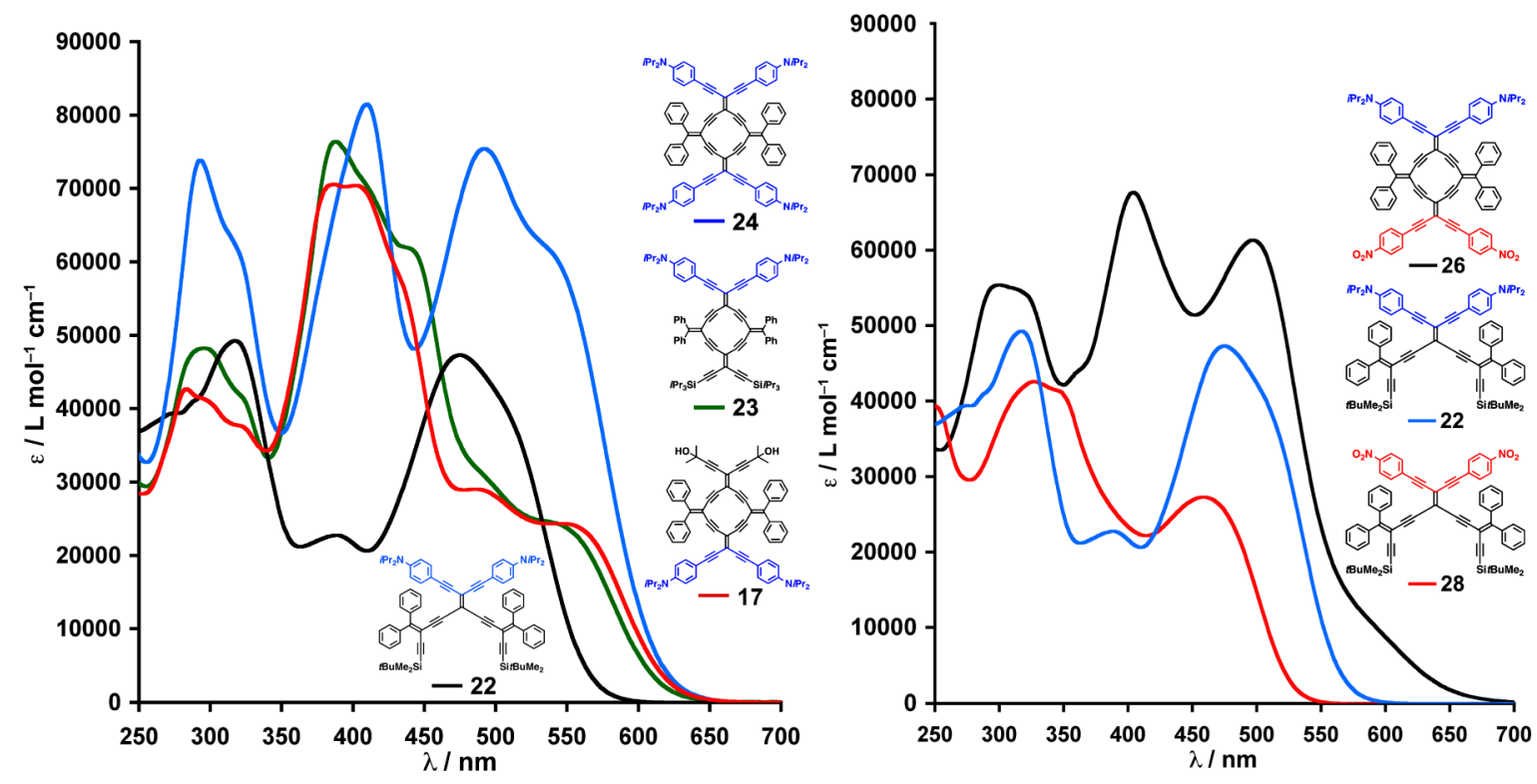

Figure 5. UV-vis absorption spectra of (a) bis-donor radialene 24 in comparison to monodonor radialenes 17 and 23 and iso-PDA 22 and (b) donoracceptor radialene $\mathbf{2 6}$ in comparison to donor and acceptor iso-PDAs 22 and $\mathbf{2 8}$, respectively. 

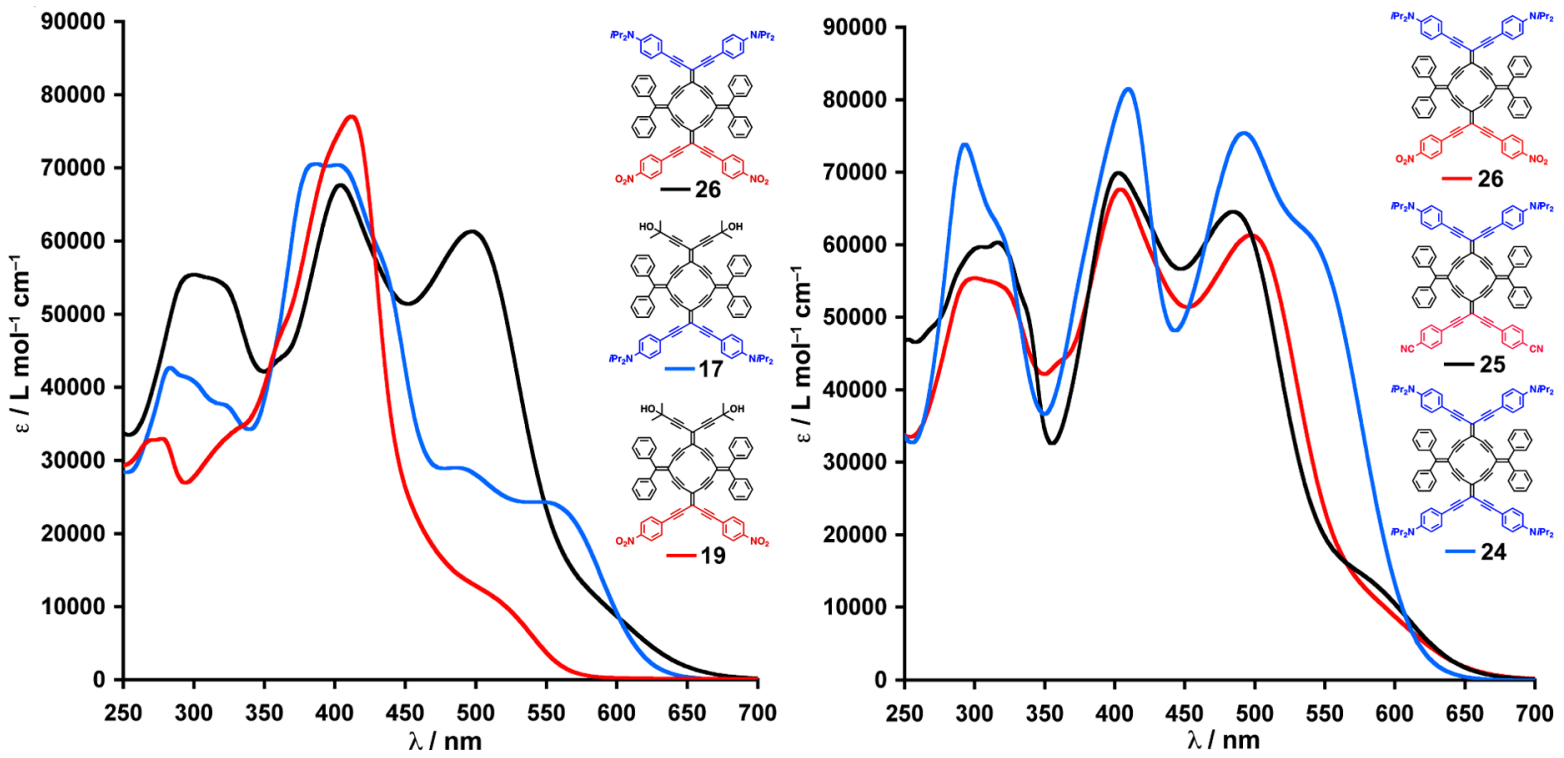

Figure 6. UV-vis absorption spectra of (a) D-A radialene 26 in comparison to donor and acceptor radialene 17 and 19, respectively, and (b) D-A radialene 25 and 26 in comparison to $\mathrm{D}-\mathrm{D}$ radialene 24 .

Table 3. Selected Electrochemical Data for Expanded [4] Radialenes (Values in $\mathrm{V})^{a}$

$\begin{array}{lccccc} & E_{\mathrm{p}} \mathrm{ox}_{1}{ }^{b} & E_{\mathrm{p}} \mathrm{ox}_{2}{ }^{b} & E_{1 / 2} \operatorname{red}_{1}{ }^{c} & E_{1 / 2} \operatorname{red}_{2}{ }^{c} & E_{\mathrm{p}} \operatorname{red}_{3}{ }^{b} \\ \mathbf{5} & 0.99 & & -1.42 & -1.75 & -2.01 \\ \mathbf{1 7} & 0.37 & 0.48 & -1.68 & -1.87 & -2.09 \\ \mathbf{1 8} & 1.05 & & -1.41 & -1.69 & \\ \mathbf{1 9} & 1.08 & & -1.35 & -1.49 & \\ \mathbf{2 3} & 0.39 & 0.48 & -1.65 & -1.95 & \\ \mathbf{2 4} & 0.35 & 0.49 & -1.52 & -1.98 & \\ \mathbf{2 5} & 0.39 & 0.49 & -1.44 & -1.72 & \\ \mathbf{2 6} & 0.37 & 0.49 & -1.40 & -1.54 & -2.02\end{array}$

${ }^{a}$ Performed at a scan rate of $150 \mathrm{mVs}^{-1}$ in deoxygenated $\mathrm{CH}_{2} \mathrm{Cl}_{2}$ containing $0.1 \mathrm{M} \mathrm{NBu}_{4} \mathrm{PF}_{6}$ as the supporting electrolyte. The concentration in analyte was about $1 \times 10^{-3} \mathrm{M}$. A $3.2 \mathrm{~mm}$ diameter Pt disk was used as the working electrode, a Pt wire was used as the counter electrode, and a $\mathrm{Ag} / \mathrm{Ag}^{+}$pseudoreference electrode was used $\left(0.01 \mathrm{M} \mathrm{AgNO}_{3}, 0.1 \mathrm{M} n \mathrm{Bu}_{4} \mathrm{NPF}_{6}\right.$ in $\left.\mathrm{CH}_{3} \mathrm{CN}\right)$. All values are versus the $\mathrm{Fc}^{+} / \mathrm{Fc}$ couple that was used as internal reference. ${ }^{b} \mathrm{Peak}$ potential, $E_{\mathrm{p}}$, for irreversible waves estimated by reporting the $E_{\mathrm{pa}}$ or $E_{\mathrm{pc}}$ values of the oxidation or reduction waves, respectively. ${ }^{c}$ Quasi-reversible, in all cases, based on the calculation $E_{1 / 2}=\left(E_{\mathrm{pc}}+E_{\mathrm{pa}}\right) / 2$, where $E_{\mathrm{pc}}$ and $E_{\mathrm{pa}}$ correspond to the cathodic and anodic peak potentials, respectively.

Electrochemical Analysis. An analysis of selected [4]radialenes from this study has been done using cyclic voltammetry, and the results are shown in Table 3 (individual CV scans are provided in the Supporting Information). In general, oxidation potentials of derivatives containing dialkylaniline moieties are dictated by the donor groups, and each shows an irreversible event in the range of $0.3-0.4 \mathrm{~V}$. In the absence of the aniline group (e.g., 5, 18, 19), the first oxidation potential is located at ca. 1.0-1.1 V, as reported for other expanded [4]radialene derivatives. ${ }^{28}$ Conversely, reduction of radialenes with only a single set of pendent dialkylaniline moieties ( 17 and 23) are quasi-reversible and located at ca. -1.7 V. Derivative 24 , with dialkylaniline substitution at both poles is slightly easier to reduce at $-1.52 \mathrm{~V}$, suggesting that the larger $\pi$-system has a greater influence on the reduction potential than the presence of additional donor groups. Finally, acceptor substituted 19 shows the most facile reduction $(-1.35 \mathrm{~V})$, qualitatively consistent with calculated LUMO energies (vide infra).

\section{THEORETICAL CONSIDERATIONS}

In order to examine the nature of the electronic transitions and to better explain the electronic features of the D/A-substituted radialenes, a series of quantum chemical calculations have been carried out. A computational approach also increases the predictive component of this study, since properties of all possible D/A substitution patterns might be explored, i.e., even those that are not yet accessible experimentally (e.g., calculated properties for $16^{\prime}$ and $29^{\prime}$ ). Most importantly, the computational results allow a much more complete analysis of the effects of ring closure and donor/acceptor functionalization.

Computational Details. The ground-state geometries were obtained using density functional theory (CAM-B3LYP ${ }^{61}$ functional and the 6-31G $(\mathrm{d}, \mathrm{p})$ basis set, as implemented in the Gaussian $09^{62}$ program). The spectrum of the molecular Hessian shows that the optimized structures represent energy minima in each case. The vertical singlet excited states and transition dipole moments were computed using time dependent density functional theory (TDDFT) with the same functional and basis set. Solvent effects were not included. CAM-B3LYP and other longrange exchange-corrected methods were shown to alleviate the problem of B3LYP and other DFT functionals to predict the structure and electronic properties of extended $\pi$-conjugated systems. ${ }^{63-66}$ For linear polyene and polyyne systems, the CAMB3LYP/6-31G $(\mathrm{d}, \mathrm{p})$ method was reported to yield structures and excitation energies ${ }^{65,66}$ that are in good agreement with experiment. In this work, the comparison of the computed values with the experimental data show excellent agreement for the structures and at least qualitative agreement for the UV-vis spectra (vide infra). When appropriate, TIPS, TBDMS, or $\mathrm{Me}_{2}(\mathrm{HO}) \mathrm{C}$ groups have been replaced with a hydrogen atom, for simplicity. Calculated structures are otherwise based on the synthesized molecules, and for clarity all calculated structures are denoted with compound numbers containing a "prime" mark relative to analogous experimental compound, e.g., donor-acceptor 
Scheme 4. Schematic Representation of the Effects of Macrocyclization and Substitution on HOMO-LUMO Energies and Transition Wavelengths ${ }^{a}$
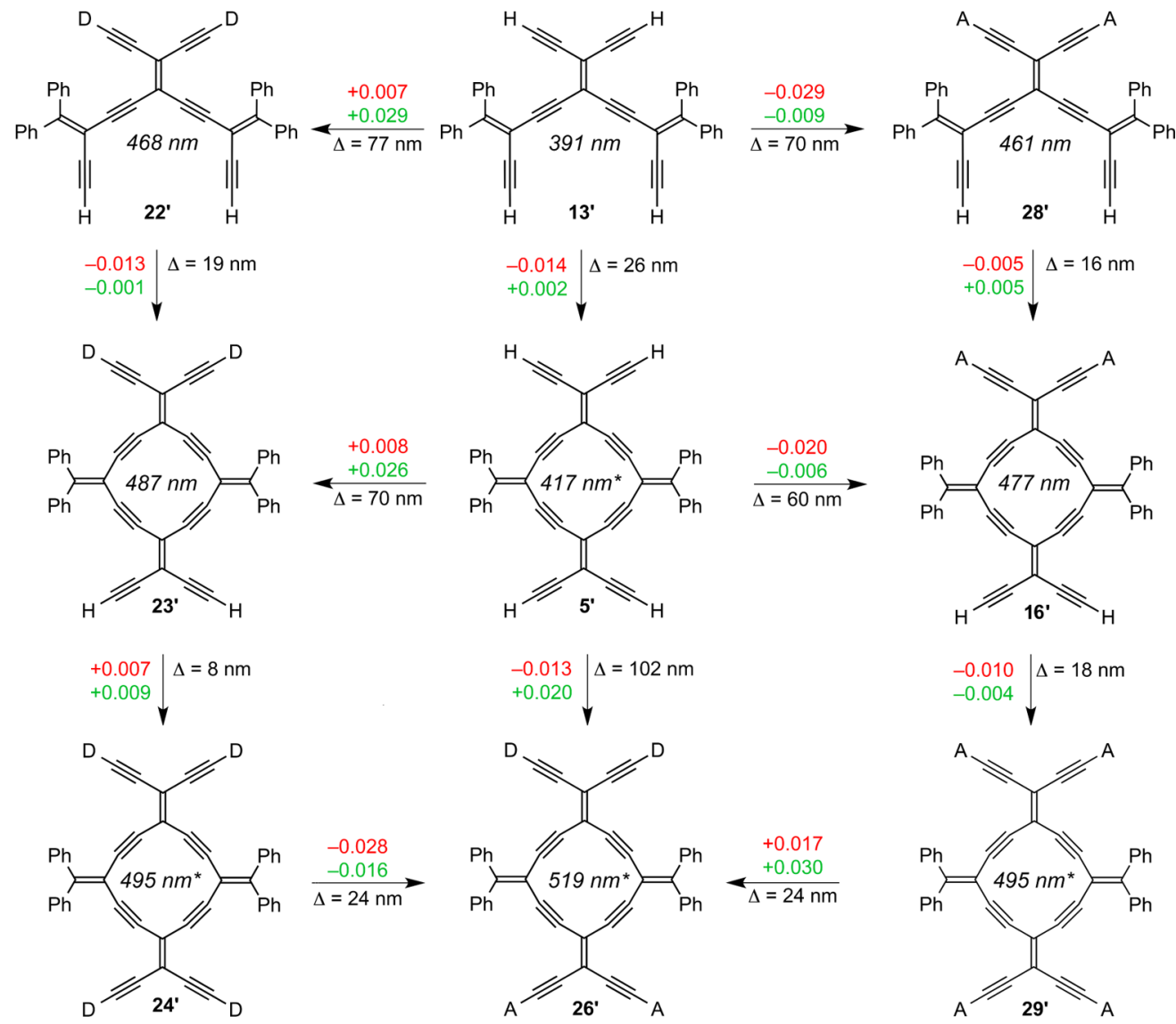

${ }^{a}$ The asterisk designates forbidden transitions; changes in HOMO and LUMO energy in atomic units ( $\Delta E$ for LUMO in red and $\Delta E$ HOMO in green) are shown above the arrow; the changes in HOMO-LUMO transition wavelength $(\Delta)$ upon functionalization are shown below the arrow, $\mathrm{D}=4-i \mathrm{Pr}_{2} \mathrm{NC}_{6} \mathrm{H}_{4}-, \mathrm{A}=4-\mathrm{O}_{2} \mathrm{NC}_{6} \mathrm{H}_{4}-$.

radialene 26 becomes $26^{\prime}$ for the calculated structure (see Scheme 4).

Comparison to Experiment: Computed and SolidState Structures. The calculated structures of radialenes $16^{\prime}$ and $23^{\prime}$ are both curved, similar to the solid-state geometry of $\mathbf{1 6}$ and $\mathbf{2 3}$ as determined by X-ray crystallography (vide supra). Contrary to the experimental solid-state structures, which show that the nitro and aniline aryl rings of the acceptor and donor groups are rotated out of plane of the radialene framework, the computed gas-phase structures predict a planarized geometry in which $\pi$-electron communication between the functionalized aryl rings is maintained with the conjugated framework of the radialene. The computed equilibrium structures are 25$30 \mathrm{~kJ} / \mathrm{mol}$ lower in energy relative to the experimental geometries, likely due to the absence of intermolecular interactions (so-called crystal packing effects). Aside from this difference in geometry, however, the agreement between computed and experimental structures for the two radialenes is very good (Table 1). The largest deviations in bond length and bond angle amount to less than $0.015 \AA$ and $3.5^{\circ}$, respectively. As expected for DFT calculations on $\pi$-conjugated compounds, there is a slight overestimation of electron delocalization, i.e., slightly shorter single bonds along with slightly longer unsaturated bonds.

Comparison to Experiment: UV-vis Absorption Spectra. The agreement between experiment and computation is very good for the longest wavelength absorptions of acyclic compounds such as $\mathbf{2 2} / \mathbf{2 2 ^ { \prime }}\left(\lambda_{\max }=475 / 468 \mathrm{~nm}\right)$ and $\mathbf{2 8} / \mathbf{2 8 ^ { \prime }}\left(\lambda_{\max }=\right.$ $459 / 461 \mathrm{~nm})$. The experimentally observed transitions for the substituted radialenes, however, consistently occur at longer wavelength than predicted by the calculations, such as donor substituted derivatives $17 / 17^{\prime}\left(\lambda_{\max }=550 / 484 \mathrm{~nm}\right)$ and $23 / 23^{\prime}$ $\left(\lambda_{\max }=544 / 487 \mathrm{~nm}\right)$.

In spite of differences between experiment and theory in absolute absorption values, specific comparisons clearly shed light on general trends for these molecules based on structure. For example, experimental measurements show a substantial redshift in $\lambda_{\max }$ absorption upon moving from an acyclic structure (e.g., $22 \lambda_{\max }=475 \mathrm{~nm}$ ) to the analogous cyclic radialene framework (e.g., $17 \lambda_{\max }=544 \mathrm{~nm}$, Figure 5a). Computations predict an analogous red shift as one moves from an acyclic structure $\left(22^{\prime} \lambda_{\max }=468 \mathrm{~nm}\right)$ to a cyclic (e.g., $\left.23^{\prime} \lambda_{\max }=487 \mathrm{~nm}\right)$, but the computed red-shift is considerably smaller than that observed experimentally. A similar observation is made through comparison of the acyclic D- and A-compounds (22 and 28, respectively) to the $\mathrm{D}-\mathrm{A}$-substituted radialene 26 (Figure $5 \mathrm{~b}$ ). The calculated $\lambda_{\max }$ value for $26^{\prime}$ (519 nm, HOMO-LUMO) is found at lower energy than either $22^{\prime}$ or $28^{\prime}\left(\lambda_{\max }=468\right.$ and $461 \mathrm{~nm})$, but the difference is less than that observed experimentally.

The computations reproduce the slight blue shift in $\lambda_{\max }$ found in the experimental spectrum of tetra-donor $\mathbf{2 4}$ radialene 
$\left(\lambda_{\max }=535 \mathrm{~nm}\right)$ in comparison to bis-donor substituted radialenes $17\left(\lambda_{\max }=550 \mathrm{~nm}\right)$ and $23\left(\lambda_{\max }=544 \mathrm{~nm}\right)$. Furthermore, the calculations suggest that the blue-shift for radialene 24 comes as a consequence of a forbidden HOMO-LUMO transition for the planar, centrosymmetric structure, ${ }^{57 \mathrm{a}, \mathrm{b}}$ i.e., the calculated HOMO-LUMO transition for $\mathbf{2 4}^{\prime}$ at $495 \mathrm{~nm}$ shows an oscillator strength $f=0$ (Table 2). Thus, $\lambda_{\max }$ for $24^{\prime}$ arises from the $\mathrm{HOMO}-1 ; \mathrm{LUMO}+1$ transition and appears at higher energy $(459 \mathrm{~nm})$ than the allowed HOMO-LUMO transition of either $17^{\prime}\left(\lambda_{\max }=484 \mathrm{~nm}\right)$ or $23^{\prime}\left(\lambda_{\max }=487 \mathrm{~nm}\right)$.

Finally, computed absorption values are also consistent with trends suggested experimentally for substituent effects mediated by the radialene framework as shown in Figure 6a, namely that the electronic structure of $\mathbf{2 6 / 2 6}$ ' is more than just a sum of the donor and acceptor parts represented by D-and A-radialenes 17/ $17^{\prime}$ and $19 / 19^{\prime}$. Or put another way, a donor-acceptor interaction, even though weak, is observed (26) and predicted $\left(26^{\prime}\right)$ for the cyclic structure based on $\lambda_{\max }$ values. The same is true when comparing the predicted $\lambda_{\max }$ values of tetra-donor and tetra-acceptor radialenes $24^{\prime}\left(\lambda_{\max }=459 \mathrm{~nm}\right)$ and $29^{\prime}\left(\lambda_{\max }=\right.$ $451 \mathrm{~nm}$; the structure of $29^{\prime}$ is shown in Scheme 4), respectively, in comparison to $26^{\prime}\left(\lambda_{\max }=519 \mathrm{~nm}\right)$.

The HOMO, the LUMO, and the Band Gap. The HOMO-LUMO transition is responsible for the lowest energy transition in all cases that have been calculated (Table 2), although in some cases this transition occurs with very low oscillator strength $(f)$ or is symmetry forbidden $(f=0)$. This fact allows one to examine an evolution of the electronic makeup of the molecules, based on molecular structure and the associated energy gap between of these two orbitals. The cycle shown in Scheme 4 was constructed to present, in a systematic way, the response in orbital energies and absorption frequencies to macrocyclization as well as to the introduction of donor and/or acceptor substituents. Scheme 4 clearly shows that starting from the acyclic iso-PDA units $\left(\mathbf{1 3}^{\prime}, \mathbf{2 2 ^ { \prime }}\right.$, and $\left.\mathbf{2 8 ^ { \prime }}\right)$, formation of the corresponding macrocycle $5^{\prime}, 23^{\prime}$, and $16^{\prime}$, respectively, results in a decrease in the HOMO-LUMO gap, i.e., macrocyclic crossconjugation is present. ${ }^{55}$ Closer inspection shows that this is mainly a result of the stabilization of the macrocycle LUMO, while the energy of the corresponding HOMO is much less affected. For the substituted pair $13^{\prime}$ and $5^{\prime}$, the HOMOLUMO energy decreases by 0.016 au upon cyclization, most of which is attributed to stabilization of the LUMO (0.014 au). Similarly, the LUMO of $23^{\prime}$ is stabilized by 0.013 au relative to $\mathbf{2 2}^{\prime}$, while the HOMO and LUMO of the acceptor substituted compound $16^{\prime}$ respond equally to ring closure (0.005 au each). Figure 7 shows that the effect of ring closure is not limited to the LUMO, but rather, that the entire band of low-lying unoccupied orbitals responds to ring formation with an energy lowering in all cases. The energies of the occupied orbitals, on the other hand, remain vastly unaffected. Hence, the red shift of $\lambda_{\max }$ values upon macrocycle formation observed experimentally and computationally appears to be a consequence of the stabilization of the unoccupied, virtual orbitals.

As one continues through the cycle in Scheme 4, the relative contributions of the donor and acceptor are also clear. Using unfunctionalized $13^{\prime}$ as a starting point, there is a strong destabilization of the HOMO $(+0.029 \mathrm{au})$ for $22^{\prime}$ upon addition of the two donors and an equally strong stabilization of the LUMO $(-0.029 \mathrm{au})$ for $\mathbf{2 8}$ ' upon acceptor substitution. If D-/Asubstituents are added directly to the radialene structure $\left(\mathbf{5}^{\prime}\right)$, the effect on the HOMO and LUMO is similar but somewhat less pronounced $(+0.026$ and -0.020 au, respectively). Thus, this

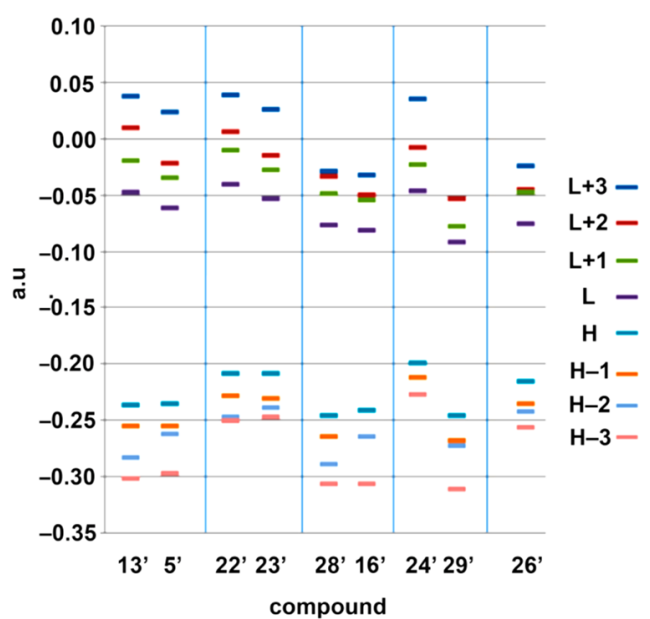

Figure 7. Energies of the frontier molecular orbitals (HOMO-3 to LUMO+3) for selected iso-PDAs and radialenes.

description is consistent with observations from experimental UV-vis spectroscopy, which show that the red-shift in $\lambda_{\max }$ is more significant upon donor substitution (compare 22 and 28, Table 2) than that for acceptor substitution (compare 23 and 16, Table 2).

The addition of a second set of donor or acceptor groups to a radialene framework (i.e., going from $23^{\prime}$ to $24^{\prime}$ and $16^{\prime}$ to $29^{\prime}$, respectively) leads to an additional, although small, reduction of the HOMO-LUMO gap. The largest effect is on the LUMO of $29^{\prime}$, which is lowered in energy by $0.010 \mathrm{au}$. An analogous conclusion comes from examination of Figure 7 , which schematically demonstrates that the energies of the individual orbital components of $\mathrm{D}-\mathrm{A}$-radialene $\mathbf{2 6 ^ { \prime }}$ arise from that of the donor (HOMO) and acceptor (LUMO) radialenes $23^{\prime}$ and 16', respectively. Or to put it another way, the lower energy LUMO of $\mathbf{1 6}^{\prime}$ and the higher energy HOMO of $23^{\prime}$ combine in $26^{\prime}$ to give the lowest energy HOMO-LUMO transition of the molecules described herein.

Observations Relating to the Charge Distributions in the HOMOs and LUMOs. Visual inspection of the frontier orbitals (Table 4) of the acyclic iso-PDAs and cyclic radialenes emphasizes several interesting aspects of the electronic structure. For example, the LUMOs of the expanded [4] radialenes show a nodeless link at all four of alkylidene intersections, thus facilitating electron delocalization in the ring system. This contrasts the construction of corresponding HOMOs, where a node is found each alkylidene unit. ${ }^{67}$ The effects of the linkage between the North and South "hemispheres" of the radialene skeleton can be appreciated by considering the scheme outlined in Figure 4. Whereas the energy of the HOMO of the expanded 4-radialenes bearing one set of substituents (i.e., 23' and 16') hardly differs from the energy of the HOMO of the corresponding iso-PDA segments (i.e., $\mathbf{2 2}^{\prime}$ and $\mathbf{2 8}^{\prime}$ ), the response of the LUMO energy is much more obvious. Thus, the nodal structure helps explain that the response of the HOMO to ring formation is much less than the one of the LUMO (i.e., comparison of $5^{\prime}$ with $13^{\prime}$ ). Finally, the largest substituent effect is found for the $\mathrm{D}-\mathrm{A}$ radialenes $25^{\prime}$ and $\mathbf{2 6}^{\prime}$, for which the LUMO is concentrated near the acceptor on the "southern" hemisphere of the radialene, while the donor dominates the HOMO on the "northern" hemisphere. This spatial separation offers the prospect of efficient photoinduced HOMO to LUMO charge-transfer. ${ }^{27}$ 
Table 4. HOMO and LUMO Orbital Plots for iso-PDAs and Expanded [4]Radialenes ${ }^{a, b}$

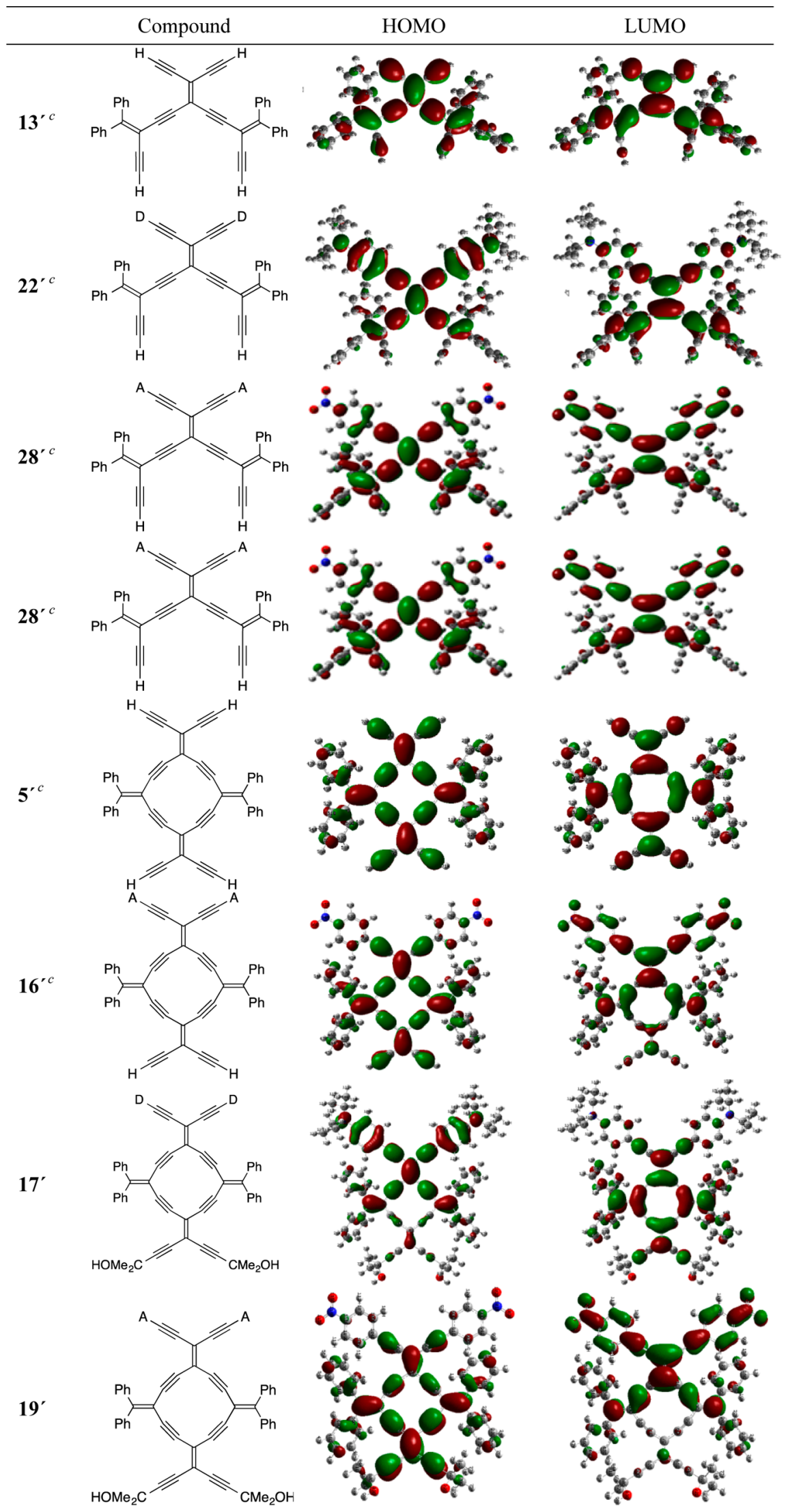


Table 4. continued

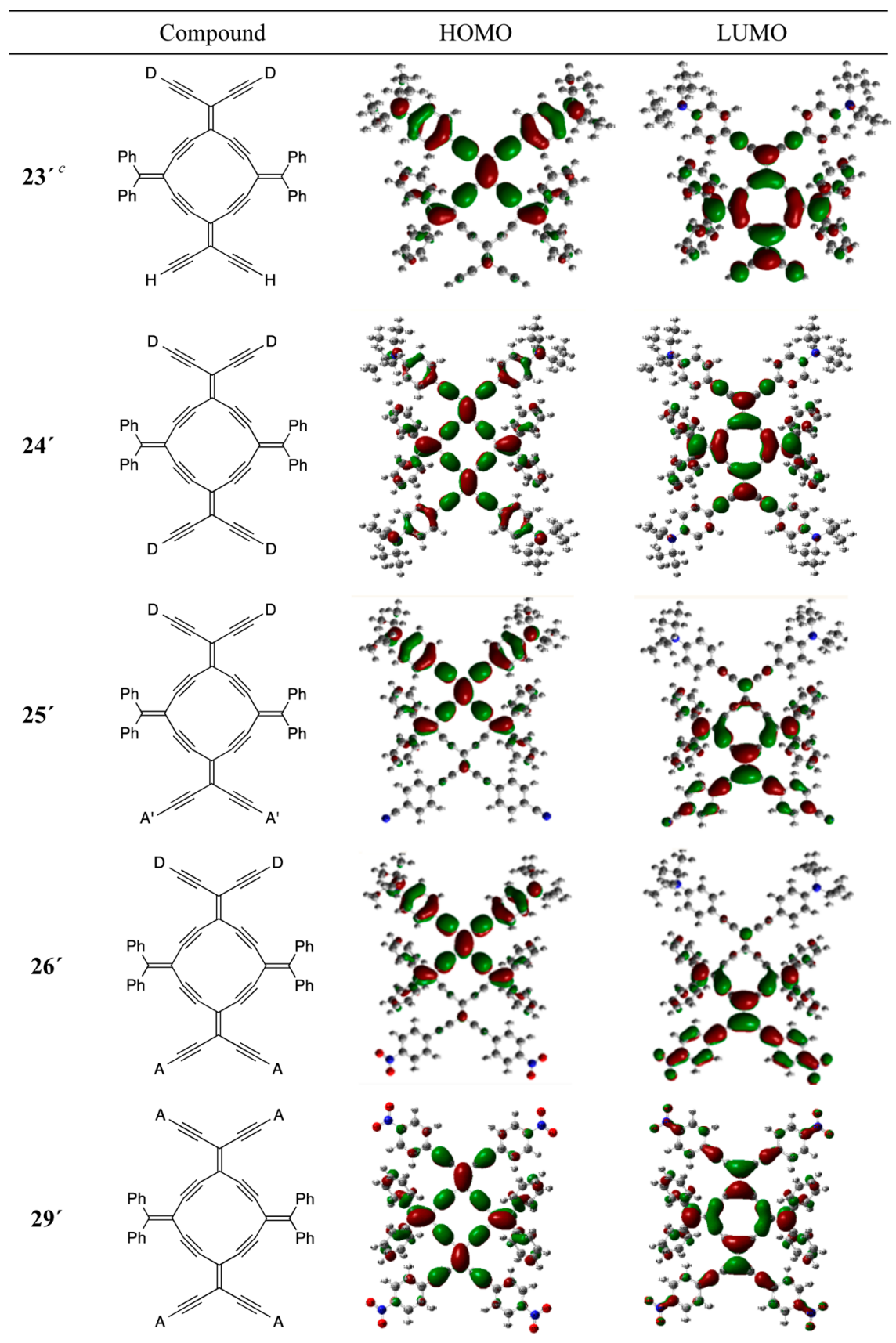

${ }^{a}$ Calculated structures are designated with a prime $\left({ }^{\prime}\right)$, referring to the experimental structure that it represents. ${ }^{b} \mathrm{D}=4-i \mathrm{Pr}_{2} \mathrm{NC}_{6} \mathrm{H}_{4}-, \mathrm{A}^{-}$ 4- $\mathrm{O}_{2} \mathrm{NC}_{6} \mathrm{H}_{4}-, \mathrm{A}^{\prime}=4-\mathrm{NCC}_{6} \mathrm{H}_{4}-.{ }^{c}$ For calculations, the $i \mathrm{Pr}_{3} \mathrm{Si}, t \mathrm{BuMe}_{2} \mathrm{Si}$, or $\mathrm{HOMe}_{2} \mathrm{C}$ group of the experimental structure has been replaced with $\mathrm{H}$.

\section{CONCLUSIONS}

In conclusion, the first examples of donor- and/or acceptor substituted expanded [4] radialenes have been synthesized using a sequence of alkyne deprotection and Sonogashira cross-coupling reactions to assemble and decorate the crossconjugated scaffolds. The UV-vis spectroscopic data for $\mathbf{2 5}$ and $\mathbf{2 6}$ show that $\mathrm{D}-\mathrm{A}$ substitution affords a smaller band gap for these radialenes as compared to either donor or acceptor substitution alone; i.e., the UV-vis spectra are not just the result of the superposition the components of the donor and acceptor fragments. This observation is supported by the computational study that shows trends in absorption spectra for acyclic iso-PDAs and cyclic radialenes mirror those found observed experimentally, in spite of small discrepancies between experimental and computational data originating from deficiencies of the quantum chemical model. More importantly, calculations also support the conclusion that the electronic absorption characteristics of D-A-radialenes are more than a simple linear combination of the individual donor and acceptor "parts" of the macrocycle. Thus, experiment and theory confirm that the [4]radialene structure does indeed provide for donor-acceptor interactions across the cross-conjugated framework, and the electronic makeup is not limited to the longest linearly conjugated segment. 


\section{EXPERIMENTAL SECTION}

General Details. Reagents were purchased in reagent grade from commercial suppliers and used without further purification. Functionalized aryl acetylenes were prepared via Sonogashira cross-coupling of the corresponding aryl halide and trimethylsilylacetylene followed by protiodesilylation using $\mathrm{K}_{2} \mathrm{CO}_{3}$ in THF/MeOH (ca. 1:5). THF and $\mathrm{Et}_{2} \mathrm{O}$ were distilled from sodium benzophenone ketyl. Anhydrous $\mathrm{MgSO}_{4}$ was used as the drying agent after aqueous workup. Filtration, evaporation, and concentration in vacuo were done at water aspirator pressure. All reactions were performed in standard, dry glassware under an inert atmosphere of argon. Column chromatography: silica gel (230400 mesh). Thin-layer chromatography (TLC): precoated plastic sheets covered with $0.20 \mathrm{~mm}$ silica gel with fluorescent indicator UV $254 \mathrm{~nm}$; visualization by UV light or $\mathrm{KMnO}_{4}$ stain. Melting points are uncorrected. ${ }^{1} \mathrm{H}$ and ${ }^{13} \mathrm{C}$ NMR spectra are collected at $27^{\circ} \mathrm{C}$ in $\mathrm{CDCl}_{3}$, $\mathrm{CD}_{2} \mathrm{Cl}_{2}, \mathrm{THF}-d_{8}$, and $\left(\mathrm{CD}_{3}\right)_{2} \mathrm{CO}$; solvent peaks as reference. Coupling constants are reported as observed $( \pm 0.5 \mathrm{~Hz})$. For simplicity, the coupling constants of the aryl protons for para-substituted aryl groups have been reported as pseudo first-order (i.e., doublets), even though they are second-order $\left(\mathrm{AA}^{\prime} \mathrm{XX}^{\prime}\right)$ spin systems.

$\mathrm{UV}$-vis spectra were acquired at $\mathrm{rt} ; \lambda_{\max }$ in $\mathrm{nm}\left(\varepsilon\right.$ in $\left.\mathrm{M}^{-1} \mathrm{~cm}^{-1}\right)$. The $\lambda_{\max }$ of shoulder absorptions are approximated to be Gaussian curves and the value of both the absorption and molar absorptivity were estimated based on this approximation. Emission spectra were recorded on deoxygenated solutions.

For mass spectral analyses, low- and high-resolution data are provided in cases when $\mathrm{M}^{+}$was not the base peak. Otherwise, only high-resolution data are provided. The samples for ESI TOF mass spectrometry were dissolved in $\mathrm{CH}_{2} \mathrm{Cl}_{2}$ and made use of a $3: 1 \mathrm{MeOH}$ /toluene mixture as the carrier solvent. MALDI TOF mass spectrometry used the matrix trans-2-[3-(4-tert-butylphenyl)-2-methyl-2-propenylidene]malononitrile (DCTB).

All thermal analyses were carried out on under a flow of nitrogen with a heating rate of $10{ }^{\circ} \mathrm{C} / \mathrm{min}$. Melting points from DSC analysis are reported as the peak maxima, except in cases when the sample decomposed, in which case the onset temperature of the decomposition exothermic peak is reported, as well as the exothermic maxima corresponding to the decomposition.

General Procedure A. Tetraethynylethene (TEE) Formation. The terminal acetylene $(10.4 \mathrm{mmol})$ was added to a degassed and dry solution of the dibromoolefin $(2.61 \mathrm{mmol})$ and THF/ $\mathrm{Et}_{3} \mathrm{~N}$ or $\mathrm{Et}_{3} \mathrm{~N}(50 \mathrm{~mL})$ in THF. $\mathrm{PdCl}_{2}\left(\mathrm{PPh}_{3}\right)_{2}(0.13 \mathrm{mmol})$ or $\mathrm{Pd}\left(\mathrm{PPh}_{3}\right)_{4}(0.13 \mathrm{mmol})$ and $\mathrm{CuI}$ $(0.26 \mathrm{mmol})$ were added sequentially and the solution stirred at $\mathrm{rt}$ until TLC analysis showed the absence of the dibromoolefinic starting material (ca. 2-3 d). $\mathrm{Et}_{2} \mathrm{O}(10 \mathrm{~mL})$ and $\mathrm{NH}_{4} \mathrm{Cl}(25 \mathrm{~mL})$ were added, the organic phase was separated, washed successively with satd aq $\mathrm{NH}_{4} \mathrm{Cl}(2 \times 50 \mathrm{~mL}), \mathrm{H}_{2} \mathrm{O}(2 \times 50 \mathrm{~mL})$, and brine $(2 \times 50 \mathrm{~mL})$, dried $\left(\mathrm{MgSO}_{4}\right)$, and filtered, and the solvent was removed in vacuo. Column chromatography (silica gel) yielded the desired TEE.

General Procedure B. iso-Polydiacetylene (iso-PDA) Formation. Unless otherwise noted in the individual procedures, a mixture of the appropriate trimethylsilyl- or triisopropylsilyl enyne and $\mathrm{K}_{2} \mathrm{CO}_{3}$ (ca. 1 equiv) or TBAF (2.2 equiv) in wet THF/MeOH $(1: 4,25 \mathrm{~mL}$ ) or THF $(25 \mathrm{~mL})$, respectively, was stirred under the conditions described in the individual procedures until the starting material was no longer visible by TLC analysis. $\mathrm{Et}_{2} \mathrm{O}(10 \mathrm{~mL})$ and saturated aq $\mathrm{NH}_{4} \mathrm{Cl}(5 \mathrm{~mL})$ were added, and the organic phase was separated, washed successively with saturated aq $\mathrm{NH}_{4} \mathrm{Cl}(2 \times 50 \mathrm{~mL}), \mathrm{H}_{2} \mathrm{O}(2 \times 50 \mathrm{~mL})$, and brine $(2 \times$ $50 \mathrm{~mL})$, dried $\left(\mathrm{MgSO}_{4}\right)$, filtered, reduced to ca. $2 \mathrm{~mL}$, and added to a deoxygenated solution of the vinyl triflate 12 ( 1 equiv per coupling event) in THF $(20 \mathrm{~mL}) . \mathrm{Pd}\left(\mathrm{PPh}_{3}\right)_{4}$ or $\mathrm{PdCl}_{2}\left(\mathrm{PPh}_{3}\right)_{2}$ (ca. 0.05 equiv), $i \mathrm{Pr}_{2} \mathrm{NH}$ or $\mathrm{Et}_{3} \mathrm{~N}$ (ca. $4 \mathrm{~mL}$ ), and $\mathrm{CuI}$ (ca. 0.10 equiv) were sequentially added, and the solution was stirred under conditions described in the individual procedures until TLC analysis no longer showed the presence of the desilylated enyne (ca. $24 \mathrm{~h}$ ). $\mathrm{Et}_{2} \mathrm{O}$ and $\mathrm{H}_{2} \mathrm{O}$ were added, the organic phase was separated, washed with saturated aq $\mathrm{NH}_{4} \mathrm{Cl}(2 \times$ $50 \mathrm{~mL}), \mathrm{H}_{2} \mathrm{O}(2 \times 50 \mathrm{~mL})$, and brine $(2 \times 50 \mathrm{~mL})$, dried $\left(\mathrm{MgSO}_{4}\right)$, and filtered, and the solvent was removed in vacuo. Flash column chromatography and/or precipitation from $\mathrm{CH}_{2} \mathrm{Cl}_{2}$ by the addition of
$\mathrm{Et}_{2} \mathrm{O}$, hexanes, or washing with $\mathrm{MeOH}$ provided the desired enyne oligomer.

General Procedure C. Radialene Formation. Unless otherwise noted in the individual procedures, a mixture of the appropriate tertbutyldimethylsilyl or triethylsilyl iso-PDA and TBAF ( 2.2 equiv) in wet THF $(10 \mathrm{~mL})$ was stirred under the conditions described in the individual procedures until the starting material was no longer visible by TLC analysis. $\mathrm{Et}_{2} \mathrm{O}(10 \mathrm{~mL})$ and saturated aq $\mathrm{NH}_{4} \mathrm{Cl}(5 \mathrm{~mL})$ were added, and the organic phase was separated, washed successively with saturated aq $\mathrm{NH}_{4} \mathrm{Cl}(2 \times 50 \mathrm{~mL}), \mathrm{H}_{2} \mathrm{O}(2 \times 50 \mathrm{~mL})$, and brine $(2 \times$ $50 \mathrm{~mL})$, dried $\left(\mathrm{MgSO}_{4}\right)$, filtered, reduced to ca. $2 \mathrm{~mL}$, and added to a deoxygenated solution of the dibromoolefin in THF $(20 \mathrm{~mL})$. $\mathrm{Pd}\left(\mathrm{PPh}_{3}\right)_{4}$ or $\mathrm{PdCl}_{2}\left(\mathrm{PPh}_{3}\right)_{2}$ (ca. 0.05 equiv), $\mathrm{Pr}_{2} \mathrm{NH}$ or $\mathrm{Et}_{3} \mathrm{~N}$, and $\mathrm{CuI}$ (ca. 0.10 equiv) were sequentially added, and the solution was refluxed until TLC analysis no longer indicated the presence of the deprotected iso-PDA (ca. 15-24 h). $\mathrm{CH}_{2} \mathrm{Cl}_{2}(10 \mathrm{~mL})$ and saturated aq $\mathrm{NH}_{4} \mathrm{Cl}$ $(5 \mathrm{~mL})$ were added, the organic phase was separated, washed successively with saturated aq $\mathrm{NH}_{4} \mathrm{Cl}(2 \times 50 \mathrm{~mL}), \mathrm{H}_{2} \mathrm{O}(2 \times 50 \mathrm{~mL})$, and brine $(2 \times 50 \mathrm{~mL})$, dried $\left(\mathrm{MgSO}_{4}\right)$, and filtered, and the solvent was removed in vacuo. Flash column chromatography and/or precipitation from $\mathrm{CH}_{2} \mathrm{Cl}_{2}$ by the addition of $\mathrm{Et}_{2} \mathrm{O}$ or hexanes or washing with $\mathrm{MeOH}$ provided the desired radialene.

General Procedure D. Radialene Functionalization. Part one, desilylation: To a solution of the appropriate triisopropylsilyl-substituted expanded [4] radialene in wet THF $(10 \mathrm{~mL})$ at $0{ }^{\circ} \mathrm{C}$ was added TBAF (2.2 equiv) and the solution stirred until the starting material was no longer visible by TLC analysis (ca. $5-10 \mathrm{~min}) . \mathrm{Et}_{2} \mathrm{O}(5 \mathrm{~mL})$ and saturated aq $\mathrm{NH}_{4} \mathrm{Cl}(2 \mathrm{~mL})$ were added at $0{ }^{\circ} \mathrm{C}$, and the organic phase was separated, washed successively with saturated aq $\mathrm{NH}_{4} \mathrm{Cl}(2 \times 50 \mathrm{~mL})$, $\mathrm{H}_{2} \mathrm{O}(2 \times 50 \mathrm{~mL})$, and brine $(2 \times 50 \mathrm{~mL})$, dried $\left(\mathrm{MgSO}_{4}\right)$, filtered, and reduced to ca. $2 \mathrm{~mL}$. Part two, cross coupling: The solution from part one was added to a degassed solution of the appropriate aryl iodide in THF $(2 \mathrm{~mL}) . \mathrm{Pd}\left(\mathrm{PPh}_{3}\right)_{4}$ (ca. 0.05 equiv), $i \mathrm{Pr}_{2} \mathrm{NH}(0.5 \mathrm{~mL}$ ), and $\mathrm{CuI}$ (ca. 0.1 equiv) were added sequentially, and the solution was stirred under conditions described in the individual procedures until TLC analysis no longer showed the presence of the deprotected radialene (ca. 15-18 h). $\mathrm{Et}_{2} \mathrm{O}(5 \mathrm{~mL})$ and saturated aq $\mathrm{NH}_{4} \mathrm{Cl}(2 \mathrm{~mL})$ were added, the organic phase was separated, washed successively with saturated aq $\mathrm{NH}_{4} \mathrm{Cl}(2 \times$ $25 \mathrm{~mL}), \mathrm{H}_{2} \mathrm{O}(2 \times 25 \mathrm{~mL})$, and brine $(2 \times 25 \mathrm{~mL})$, dried $\left(\mathrm{MgSO}_{4}\right)$, and filtered, and the solvent was removed in vacuo. Flash column chromatography and/or precipitation/washing with $\mathrm{Et}_{2} \mathrm{O}$, hexanes, or $\mathrm{MeOH}$ provided the functionalized expanded radialene.

Radialene 5. iso-PDA $13(0.024 \mathrm{~g}, 0.027 \mathrm{mmol})$ was desilylated using TBAF (0.05 mL, $0.05 \mathrm{mmol}, 1.0 \mathrm{M}$ in THF) and cross-coupled with dibromoolefin $7(0.015 \mathrm{~g}, 0.027 \mathrm{mmol})$ according to general procedure C. Flash column chromatography (silica gel, EtOAc/hexanes $1: 9 \rightarrow 3: 7)$ and two-solvent recrystallization using $\mathrm{CH}_{2} \mathrm{Cl}_{2} /$ hexanes at $5{ }^{\circ} \mathrm{C}$ provided $5(0.0084 \mathrm{~g}, 30 \%)$ as a yellow solid: $\mathrm{mp} 201-202{ }^{\circ} \mathrm{C}$ (discolors, dec); $R_{f}=0.52$ (EtOAc/hexanes 1:1); UV-vis $\left(\mathrm{CH}_{2} \mathrm{Cl}_{2}\right)$ $\lambda_{\max }\left(\varepsilon \mathrm{L} \mathrm{mol}^{-1} \mathrm{~cm}^{-1}\right) 436$ (sh, 29900), $393(127800), 275(31000) \mathrm{nm}$; IR $\left(\mathrm{CH}_{2} \mathrm{Cl}_{2}\right.$, cast $) 3402$ (br), 3083, 3054, 2942, 2865, 2168, 2136, $1278 \mathrm{~cm}^{-1} ;{ }^{1} \mathrm{H}$ NMR $\left(400 \mathrm{MHz}, \mathrm{CDCl}_{3}\right) \delta 7.42-7.37(\mathrm{~m}, 14 \mathrm{H}), 7.31-$ $7.28(\mathrm{~m}, 6 \mathrm{H}), 1.45(\mathrm{~s}, 2 \mathrm{H}), 1.31(\mathrm{~s}, 12 \mathrm{H}), 0.94-0.85(\mathrm{~m}, 42 \mathrm{H}) \mathrm{ppm}$; ${ }^{13} \mathrm{C}$ NMR $\left(100 \mathrm{MHz}, \mathrm{CDCl}_{3}\right) \delta 153.4,140.6,139.6,131.1,130.8,129.5$, 129.2, 128.0, 127.9, 117.5, 116.8, 111.9, 110.1, 104.0, 103.7, 103.6, 102.7, 102.5, 101.9, 96.2, 95.1, 79.5, 65.4, 30.9, 18.6, 11.2 ppm; HRMS MALDI $m / z$ calcd for $\mathrm{C}_{72} \mathrm{H}_{76} \mathrm{O}_{2} \mathrm{Si}_{2}[\mathrm{M}]^{+} 1028.5378$, found 1028.5377. DSC: $\mathrm{mp}$ $189^{\circ} \mathrm{C}$; dec $203^{\circ} \mathrm{C}$ (onset), $205^{\circ} \mathrm{C}$ (peak).

TEE 10. Dibromoolefin $7(2.81 \mathrm{~g}, 5.14 \mathrm{mmol})$ and 2-methyl-3butyn-2-ol $(1.73 \mathrm{~g}, \mathrm{~mL}, 12.00 \mathrm{~mL}, 20.6 \mathrm{mmol})$ were subjected to TEE formation in $\mathrm{Et}_{3} \mathrm{~N} / \mathrm{THF}(1: 1 \mathrm{v} / \mathrm{v}, 25 \mathrm{~mL})$ for $1 \mathrm{~d}$ according to general procedure A to afford $10(2.274 \mathrm{~g}, 80 \%)$ as a colorless solid: $\mathrm{mp} 110$ $112{ }^{\circ} \mathrm{C}$ (discolors, dec); $R_{f}=0.37$ (EtOAc/hexanes 3:10); IR $\left(\mathrm{CH}_{2} \mathrm{Cl}_{2}\right.$, cast) 3344 (br), 2944, 2866, 2208, 2146, $1240 \mathrm{~cm}^{-1}$; ${ }^{1} \mathrm{H} \mathrm{NMR}(500 \mathrm{MHz}$, $\left.\mathrm{CDCl}_{3}\right) \delta 2.02(\mathrm{~s}, 2 \mathrm{H}), 1.55(\mathrm{~s}, 12 \mathrm{H}), 1.10(\mathrm{~s}, 42 \mathrm{H}) \mathrm{ppm} ;{ }^{13} \mathrm{C}$ NMR $(125$ $\mathrm{MHz}, \mathrm{CDCl}_{3}$, APT) $\delta 117.8,116.0,103.6,102.7,101.5,79.7,65.7,31.1$, 18.7, 11.2 ppm; ESI HRMS calcd for $\mathrm{C}_{34} \mathrm{H}_{56} \mathrm{NaO}_{2} \mathrm{Si}_{2}\left([\mathrm{M}+\mathrm{Na}]^{+}\right)$ 575.3711, found 575.3714. Anal. Calcd for $\mathrm{C}_{34} \mathrm{H}_{56} \mathrm{O}_{2} \mathrm{Si}_{2}$ : C, 73.85; H, 10.21. Found: $\mathrm{C}, 73.79 ; \mathrm{H}, 10.24$. 
iso-PDA 13. Compound $10(0.31 \mathrm{~g}, 0.56 \mathrm{mmol})$ was desilylated using TBAF (1.2 mL, $1.2 \mathrm{mmol}, 1.0 \mathrm{M}$ in THF) and cross-coupled with vinyl triflate $12(0.522 \mathrm{~g}, 1.12 \mathrm{mmol})$ in deoxygenated THF $(5 \mathrm{~mL})$ in the presence of $\mathrm{Pd}\left(\mathrm{PPh}_{3}\right)_{4}(0.032 \mathrm{~g}, 0.028 \mathrm{mmol}), i \mathrm{Pr}_{2} \mathrm{NH}(2 \mathrm{~mL})$, and $\mathrm{CuI}(0.011 \mathrm{~g}, 0.056 \mathrm{mmol})$ for $24 \mathrm{~h}$ at reflux according to general procedure B. Flash column chromatography (silica gel, EtOAc/hexanes $1: 5 \rightarrow 1: 1)$ provided compound $13(0.42 \mathrm{~g}, 86 \%)$ as a yellow foam: $\mathrm{mp}$ 59-63 ${ }^{\circ} \mathrm{C} ; R_{f}=0.43\left(\mathrm{CH}_{2} \mathrm{Cl}_{2} /\right.$ hexanes 3:7); UV-vis $\left(\mathrm{CH}_{2} \mathrm{Cl}_{2}\right) \lambda_{\max }$ $\left(\varepsilon \mathrm{L} \mathrm{mol}^{-1} \mathrm{~cm}^{-1}\right) 395$ (28400), 319 (26400), 255 (37800) nm; IR $\left(\mathrm{CH}_{2} \mathrm{Cl}_{2}\right.$, microscope) 3566, 3373 (br), 3082, 3055, 2981, 2954, 2929, $2857,2184,2142,1250 \mathrm{~cm}^{-1} ;{ }^{1} \mathrm{H}$ NMR $\left(500 \mathrm{MHz}, \mathrm{CDCl}_{3}\right) \delta 7.40-7.25$ $(\mathrm{m}, 20 \mathrm{H}), 1.87(\mathrm{~s}, 2 \mathrm{H}), 1.49(\mathrm{~s}, 12 \mathrm{H}), 0.79(\mathrm{~s}, 18 \mathrm{H}), 0.03(\mathrm{~s}, 12 \mathrm{H}) \mathrm{ppm}$; ${ }^{13} \mathrm{C}$ NMR $\left(125 \mathrm{MHz}, \mathrm{CDCl}_{3}\right.$, APT) $\delta 158.6,140.3,139.6,130.4,130.3$, 128.9, 128.5, 127.8, 127.7, 118.3, 115.2, 103.4, 103.0, 101.3, 97.1, 96.6, 88.2, 79.5, 65.5, 31.0, 26.0, 16.7, -4.8 ppm; ESI MS $m / z$ HRMS calcd for $\mathrm{C}_{60} \mathrm{H}_{64} \mathrm{O}_{2} \mathrm{Si}_{2} \mathrm{Na}[\mathrm{M}+\mathrm{Na}]^{+}$895.4337, found 895.4339. DSC: $\mathrm{mp}=$ $63{ }^{\circ} \mathrm{C}$.

Radialene 15. Compound 5 ( $23 \mathrm{mg}, 0.022 \mathrm{mmol})$ was combined with $\mathrm{KOH}(0.002 \mathrm{~g}, 0.03 \mathrm{mmol})$ in $\mathrm{C}_{6} \mathrm{H}_{6}(10 \mathrm{~mL})$ at reflux until the starting material was no longer visible by TLC analysis (ca. $30 \mathrm{~min}$ ). The reaction was cooled to rt, and $\mathrm{Et}_{2} \mathrm{O}(5 \mathrm{~mL})$ and saturated aq $\mathrm{NH}_{4} \mathrm{Cl}$ $(2 \mathrm{~mL})$ were added. The organic phase was separated, washed successively with saturated aq $\mathrm{NH}_{4} \mathrm{Cl}(2 \times 50 \mathrm{~mL})$, brine $(2 \times 50 \mathrm{~mL})$, dried $\left(\mathrm{MgSO}_{4}\right)$, filtered, and reduced to ca. $2 \mathrm{~mL}$. This solution was then carried on to a cross-coupling reaction with 4-iodobenzonitrile $(10 \mathrm{mg}$, $0.045 \mathrm{mmol})$ in the presence of $i \mathrm{Pr}_{2} \mathrm{NH}(2 \mathrm{~mL}), \mathrm{Pd}\left(\mathrm{PPh}_{3}\right)_{4}(1 \mathrm{mg}$, $0.001 \mathrm{mmol})$, and $\mathrm{CuI}(2 \mathrm{mg}, 0.002 \mathrm{mmol})$ for $40 \mathrm{~h}$ according to part 2 of general procedure $\mathrm{D}$ (cross coupling). Column chromatography (silica gel, $\left.\mathrm{CH}_{2} \mathrm{Cl}_{2}\right)$ afforded 15 as an orange solid $(12.7 \mathrm{mg}, 52 \%): \mathrm{mp}=$ $218-220{ }^{\circ} \mathrm{C}$ (discolors, dec); $R_{f}=0.68\left(\mathrm{CH}_{2} \mathrm{Cl}_{2}\right)$. UV-vis $\left(\mathrm{CH}_{2} \mathrm{Cl}_{2}\right)$ $\lambda_{\max }\left(\varepsilon \mathrm{L} \mathrm{mol}^{-1} \mathrm{~cm}^{-1}\right) 414$ (63900), 339 (27400), 265 (30100) nm; IR ( $\mathrm{CH}_{2} \mathrm{Cl}_{2}$, cast) $3050,2921,2859,2359,2228,2163,1602,1461 \mathrm{~cm}^{-1}$; ${ }^{1} \mathrm{H}$ NMR $\left(400 \mathrm{MHz}, \mathrm{CD}_{2} \mathrm{Cl}_{2}\right) \delta 7.61(\mathrm{~d}, J=8.8 \mathrm{~Hz}, 4 \mathrm{H}), 7.43-7.37(\mathrm{~m}$, $8 \mathrm{H}), 7.36-7.31(\mathrm{~m}, 6 \mathrm{H}), 7.27(\mathrm{~d}, J=8.4 \mathrm{~Hz}, 4 \mathrm{H}), 7.12(\mathrm{t}, J=8.0 \mathrm{~Hz}$, $4 \mathrm{H}), 6.98-6.94(\mathrm{~m}, 2 \mathrm{H}), 0.94-0.83(\mathrm{~s}, 42 \mathrm{H}) \mathrm{ppm} ;{ }^{13} \mathrm{C} \mathrm{NMR}$ $\left(100 \mathrm{MHz}, \mathrm{CD}_{2} \mathrm{Cl}_{2}\right) \delta 155.4,140.2,139.7,132.7,132.4,131.2,131.1$, $130.2,129.8,128.3,128.2,127.0,119.9,118.7,116.5,112.7,112.3,109.3$, 106.4, 104.1, 103.8, 103.7, 101.4, 96.51, 95.1, 90.0, 18.7, 11.5 ppm (one signal coincident or not observed); HRMS ESI $\mathrm{m} / z$ calcd for $\mathrm{C}_{80} \mathrm{H}_{70} \mathrm{~N}_{2} \mathrm{Si}_{2} \mathrm{Na}\left([\mathrm{M}+\mathrm{Na}]^{+}\right)$1137.4970, found 1137.4963 .

Radialene 16. Compound $5(23 \mathrm{mg}, 0.022 \mathrm{mmol})$ was combined with $\mathrm{KOH}(0.002 \mathrm{~g}, 0.033 \mathrm{mmol})$ in $\mathrm{C}_{6} \mathrm{H}_{6}(10 \mathrm{~mL})$ at reflux until the starting material was no longer visible by TLC analysis (ca. $30 \mathrm{~min}$ ). The reaction was cooled to rt, and $\mathrm{Et}_{2} \mathrm{O}(5 \mathrm{~mL})$ and saturated aq $\mathrm{NH}_{4} \mathrm{Cl}$ $(2 \mathrm{~mL})$ were added. The organic phase separated, washed successively with saturated aq $\mathrm{NH}_{4} \mathrm{Cl}(2 \times 50 \mathrm{~mL})$, brine $(2 \times 50 \mathrm{~mL})$, dried $\left(\mathrm{MgSO}_{4}\right)$, filtered, and reduced to ca. $2 \mathrm{~mL}$. This solution was then carried on to a cross-coupling reaction with 4-iodonitrobenzene $(10 \mathrm{mg}$, $0.045 \mathrm{mmol})$ in the presence of $i \mathrm{Pr}_{2} \mathrm{NH}(2 \mathrm{~mL}), \mathrm{Pd}\left(\mathrm{PPh}_{3}\right)_{4}(1 \mathrm{mg}$, $0.001 \mathrm{mmol})$, and $\mathrm{CuI}(2 \mathrm{mg}, 0.002 \mathrm{mmol})$ for $40 \mathrm{~h}$ according to the second part of general procedure D (cross coupling). Column chromatography (silica gel, $\mathrm{CH}_{2} \mathrm{Cl}_{2} /$ hexanes $1: 1$ ) afforded 16 as an orange solid (2.8 mg, 13\%): $R_{f}=0.38\left(\mathrm{CH}_{2} \mathrm{Cl}_{2} /\right.$ hexanes $\left.1: 1\right) ; R_{f}=0.68$ $\left(\mathrm{CH}_{2} \mathrm{Cl}_{2}\right) ;{ }^{1} \mathrm{H}$ NMR $\left(300 \mathrm{MHz}, \mathrm{CD}_{2} \mathrm{Cl}_{2}\right) \delta 8.18(\mathrm{~d}, J=9.0 \mathrm{~Hz}, 4 \mathrm{H})$, $7.45-7.43(\mathrm{~m}, 8 \mathrm{H}), 7.44-7.36(\mathrm{~m}, 10 \mathrm{H}), 7.17(\mathrm{t}, J=8.0 \mathrm{~Hz}, 4 \mathrm{H}), 6.98$ $(\mathrm{t}, J=7.4 \mathrm{~Hz}, 2 \mathrm{H}), 0.93(\mathrm{~s}, 42 \mathrm{H}) \mathrm{ppm} ;{ }^{13} \mathrm{C} \mathrm{NMR}\left(100 \mathrm{MHz}, \mathrm{CDCl}_{3}\right) \delta$ 154.6, 147.3, 139.9, 139.3, 132.7, 131.0, 130.8, 129.7, 129.4, 128.9, 127.9, 127.8, 123.4, 116.4, 112.3, 108.2, 106.7, 103.8, 103.4, 103.0, 101.3, 99.6, 96.44, 95.7, 95.1, 91.0, 18.5, $11.1 \mathrm{ppm}$ (spectrum suffers from low $\mathrm{S} / \mathrm{N}$ due to limited solubility, see the Supporting Information).

A crystal suitable for X-ray crystallography was grown from a $\mathrm{CH}_{2} \mathrm{Cl}_{2}$ solution of 16 which had been layered with hexanes and allowed to slowly evaporate in the refrigerator at $4{ }^{\circ} \mathrm{C}$. X-ray crystallographic data for 16: $\mathrm{C}_{78} \mathrm{H}_{70} \mathrm{~N}_{2} \mathrm{O}_{4} \mathrm{Si}_{2} \cdot 0.5 \mathrm{CH}_{2} \mathrm{Cl}_{2}, M=1198.00$; triclinic space group $P-1 ; \rho_{\text {calcd }}=1.153 \mathrm{~g} \mathrm{~cm}^{-3} ; a=14.4760(4) \AA, b=15.8680(4) \AA, c=$ $16.718(3) \AA ; \alpha=77.232(2)^{\circ}, \beta=81.703(2)^{\circ}, \gamma=67.4630(10)^{\circ} ; V=$ $3451.6(7) \AA^{3} ; Z=2 ; \mu=0.140 \mathrm{~mm}^{-1}$. Final $R_{1}(\mathrm{~F})=R_{1}=0.0851(8325$ observations) $\left[F_{0}^{2} \geq 2 \sigma\left(F_{0}^{2}\right)\right] ; w R_{2}=0.2569$ for 825 variables, 5 restraints, and 12105 data with $\left[F_{0}^{2} \geq-3 \sigma\left(F_{0}^{2}\right)\right]$; largest diff peak and hole 0.791 and -0.717 e $\AA^{-3}$. Disorder within the triisopropylsilyl groups was refined with the following occupancies: C104:C120 = 68:32\% and C108/109:C121/C122 = 79:21\%. CCDC 1012585 .

Radialene 17. Compound $5(0.025 \mathrm{~g}, 0.024 \mathrm{mmol})$ was desilylated and cross-coupled with 4-iodo- $\mathrm{N}, \mathrm{N}$-diisopropylaniline (0.015 g, $0.048 \mathrm{mmol})$ in the presence of $i \operatorname{Pr}_{2} \mathrm{NH}(2 \mathrm{~mL}), \mathrm{Pd}\left(\mathrm{PPh}_{3}\right)_{4}(0.001 \mathrm{~g}$, $0.001 \mathrm{mmol})$, and $\mathrm{CuI}(0.0004 \mathrm{~g}, 0.002 \mathrm{mmol})$ according to general procedure D. Flash column chromatography (silica gel, EtOAc/hexanes $1: 5 \rightarrow 3: 5)$ followed by washing with $\mathrm{Et}_{2} \mathrm{O}$ afforded 17 as a red solid $(0.019 \mathrm{~g}, 79 \%): \mathrm{mp} 233-235{ }^{\circ} \mathrm{C}$ (discolors, dec); $R_{f}=0.38$ (EtOAc/ hexanes 1:1); UV-vis $\left(\mathrm{CH}_{2} \mathrm{Cl}_{2}\right) \lambda_{\max }\left(\varepsilon \mathrm{L} \mathrm{mol}^{-1} \mathrm{~cm}^{-1}\right) 550$ (24300), 486 (29000), 403 (70400), 397 (72600), 387 (70600), 283 (42700) $\mathrm{nm}$; fluorescence $\left(\mathrm{CH}_{2} \mathrm{Cl}_{2}, \lambda_{\text {exc }}=425 \mathrm{~nm}\right): \lambda_{\max , \mathrm{em}}=659 \mathrm{~nm}$; IR $\left(\mathrm{CH}_{2} \mathrm{Cl}_{2}\right.$, cast $) 3375(\mathrm{br}), 3052,2972,2928,2170,1602,1294 \mathrm{~cm}^{-1} ;{ }^{1} \mathrm{H}$ NMR $\left(500 \mathrm{MHz}, \mathrm{CD}_{2} \mathrm{Cl}_{2}\right) \delta 7.49-7.46(\mathrm{~m}, 4 \mathrm{H}), 7.44-7.38(\mathrm{~m}, 10 \mathrm{H})$, $7.22-7.18(\mathrm{~m}, 4 \mathrm{H}), 7.16-7.12(\mathrm{~m}, 2 \mathrm{H}), 6.94(\mathrm{~d}, J=9.1 \mathrm{~Hz}, 4 \mathrm{H}), 6.70$ $(\mathrm{d}, J=9.1 \mathrm{~Hz}, 4 \mathrm{H}), 3.92$ (septet, $J=6.9 \mathrm{~Hz}, 4 \mathrm{H}), 1.50(\mathrm{~s}, 2 \mathrm{H}), 1.32(\mathrm{~d}$, $J=6.9 \mathrm{~Hz}, 24 \mathrm{H}), 1.26(\mathrm{~s}, 12 \mathrm{H}) \mathrm{ppm} ;{ }^{13} \mathrm{C}$ NMR $\left(125 \mathrm{MHz}, \mathrm{CD}_{2} \mathrm{Cl}_{2}\right) \delta$ $153.2,149.3,140.8,140.0,133.2,131.3,131.0,129.7,129.6,128.4,128.3$, $117.4,115.6,114.2,112.2,110.5,108.6,104.0,103.4,102.7,102.2,101.6$, 97.3, 95.6, 86.7, 79.5, 65.6, 47.9, 31.1, $21.2 \mathrm{ppm}$; HRMS MALDI $\mathrm{m} / \mathrm{z}$ calcd for $\mathrm{C}_{78} \mathrm{H}_{70} \mathrm{~N}_{2} \mathrm{O}_{2}[\mathrm{M}]^{+}$1066.5432, found 1066.5432. DSC: dec $226{ }^{\circ} \mathrm{C}$ (onset), $230{ }^{\circ} \mathrm{C}$ (peak).

Radialene 18. Compound $5(0.025 \mathrm{~g}, 0.024 \mathrm{mmol})$ was desilylated and cross-coupled with 4-iodobenzonitrile $(0.011 \mathrm{~g}, 0.048 \mathrm{mmol})$ in the presence of $i \mathrm{Pr}_{2} \mathrm{NH}(2 \mathrm{~mL}), \mathrm{Pd}\left(\mathrm{PPh}_{3}\right)_{4}(0.001 \mathrm{~g}, 0.001 \mathrm{mmol})$, and $\mathrm{CuI}$ $(0.0004 \mathrm{~g}, 0.002 \mathrm{mmol})$ according to general procedure D. Silica gel filtration $\left(\mathrm{CH}_{2} \mathrm{Cl}_{2}\right)$ followed by washing with $\mathrm{Et}_{2} \mathrm{O}$ afforded 18 as an orange solid $(0.022 \mathrm{~g}, 99 \%): R_{f}=0.47$ (THF/hexanes 1:1). UV-vis $\left(\mathrm{CH}_{2} \mathrm{Cl}_{2}\right) \lambda_{\max }\left(\varepsilon \mathrm{L} \mathrm{mol}^{-1} \mathrm{~cm}^{-1}\right) 482$ (sh, 14800), 409 (93800), 339 (47200), $265(43500) \mathrm{nm}$; fluorescence $\left(\mathrm{CH}_{2} \mathrm{Cl}_{2}, \lambda_{\text {exc }}=425 \mathrm{~nm}\right) \lambda_{\text {max,em }}=$ $574 \mathrm{~nm}$; IR $\left(\mathrm{CH}_{2} \mathrm{Cl}_{2}\right.$, cast $) 3482$ (br), 3059, 2981, $22241602,1275 \mathrm{~cm}^{-1}$; ${ }^{1} \mathrm{H}$ NMR $\left(500 \mathrm{MHz}, \mathrm{THF}-d_{8}\right) \delta 7.69(\mathrm{~d}, J=8.5 \mathrm{~Hz}, 4 \mathrm{H}), 7.44-7.37(\mathrm{~m}$, $14 \mathrm{H}), 7.27(\mathrm{~d}, J=8.5 \mathrm{~Hz}, 4 \mathrm{H}), 7.22(\mathrm{t}, J=7.7 \mathrm{~Hz}, 4 \mathrm{H}), 7.06(\mathrm{t}, J=7.4 \mathrm{~Hz}$, 2H), 4.42 (s, 2H), $1.17(\mathrm{~s}, 12 \mathrm{H})$ ppm; ${ }^{13} \mathrm{C}$ NMR $\left(125 \mathrm{MHz}, \mathrm{THF}-d_{8}\right) \delta$ $155.6,140.9,140.5,133.3,132.9,131.6,131.4,130.8,130.6,129.3,128.9$, 127.2, 120.5, 118.7, 116.2, 113.7, 113.2, 109.7, 107.0, 106.2, 103.0, 102.2, 97.3, 96.9, 96.1, 90.3, 79.5, 64.9, 31.7 ppm; HRMS ESI $m / z$ calcd for $\mathrm{C}_{68} \mathrm{H}_{42} \mathrm{~N}_{2} \mathrm{O}_{2} \mathrm{Na}[\mathrm{M}+\mathrm{Na}]^{+}$941.3139, found 941.3030. DSC: dec $194{ }^{\circ} \mathrm{C}$ (onset), $199^{\circ} \mathrm{C}$ (peak).

Radialene 19. Compound $5(0.016 \mathrm{~g}, 0.016 \mathrm{mmol})$ was desilylated and cross-coupled with 4-iodonitrobenzene $(0.0080 \mathrm{~g}, 0.032 \mathrm{mmol})$ in the presence of $i \mathrm{Pr}_{2} \mathrm{NH}(2 \mathrm{~mL}), \mathrm{Pd}\left(\mathrm{PPh}_{3}\right)_{4}(0.001 \mathrm{~g}, 0.001 \mathrm{mmol})$, and $\mathrm{CuI}(0.0004 \mathrm{~g}, 0.002 \mathrm{mmol})$ according to general procedure $\mathrm{D}$. Silica gel filtration $\left(\mathrm{CH}_{2} \mathrm{Cl}_{2}\right)$ and washing with $\mathrm{Et}_{2} \mathrm{O}$ afforded 19 as an orange solid (0.015 g, 99\%): $\mathrm{mp} 208-210^{\circ} \mathrm{C}$ (discolors, dec); $R_{f}=0.66$ (THF/ hexanes 1:1); UV-vis $\left(\mathrm{CH}_{2} \mathrm{Cl}_{2}\right) \lambda_{\max }\left(\varepsilon \mathrm{L} \mathrm{mol}^{-1} \mathrm{~cm}^{-1}\right) 500$ (sh, 12900), 412 (77000), $277(33000) \mathrm{nm}$; fluorescence $\left(\mathrm{CH}_{2} \mathrm{Cl}_{2}, \lambda_{\text {exc }}=425 \mathrm{~nm}\right)$ : $\lambda_{\text {max,em }}=595 \mathrm{~nm} ; \mathrm{IR}\left(\mathrm{CH}_{2} \mathrm{Cl}_{2}\right.$, cast $) 3548,3446,3051,2930,2170,1342$ $\mathrm{cm}^{-1} ;{ }^{1} \mathrm{H}$ NMR $\left(500 \mathrm{MHz}, \mathrm{THF}-d_{8}\right) \delta 8.19(\mathrm{~d}, J=9.0 \mathrm{~Hz}, 4 \mathrm{H}), 7.45-$ $7.40(\mathrm{~m}, 14 \mathrm{H}), 7.37(\mathrm{~d}, J=9.0 \mathrm{~Hz}, 4 \mathrm{H}), 7.22(\mathrm{t}, J=8.0 \mathrm{~Hz}, 4 \mathrm{H}), 7.04(\mathrm{t}$, $J=7.4 \mathrm{~Hz}, 2 \mathrm{H}), 4.43(\mathrm{~s}, 2 \mathrm{H}), 1.18(\mathrm{~s}, 12 \mathrm{H}) \mathrm{ppm} ;{ }^{13} \mathrm{C} \mathrm{NMR}(125 \mathrm{MHz}$, THF- $\left.d_{8}\right) \delta 155.8,148.8,140.8,140.5,133.7,131.6,131.5,130.8,130.6$, $129.3,129.2,128.9,124.3,121.0,116.2,113.3,109.4,107.3,106.2,103.0$, 102.2, 97.0, 96.9, 96.1, 90.9, 79.5, 64.9, 31.7 ppm; HRMS MALDI $\mathrm{m} / z$ calcd for $\mathrm{C}_{66} \mathrm{H}_{42} \mathrm{~N}_{2} \mathrm{O}_{6}[\mathrm{M}]^{+}$958.3037, found 958.3035. DSC: dec $179^{\circ} \mathrm{C}$ (onset), $190{ }^{\circ} \mathrm{C}$ (peak).

TEE 20. 1,1-Dibromo-4-(trimethylsilyl)-2-[(trimethylsilyl)ethynyl] 1-buten-3-yne ${ }^{51}(1.37 \mathrm{~g}, 3.62 \mathrm{mmol})$ and $p$-ethynyl- $N, N$-diisopropylaniline $(1.95 \mathrm{~g}, 22.2 \mathrm{mmol})$ were subjected to TEE formation in $\mathrm{Et}_{3} \mathrm{~N}$ $(20 \mathrm{~mL})$ for $3 \mathrm{~d}$ according to general procedure A to afford $20(1.20 \mathrm{~g}$, $54 \%$ ) as an orange solid: $\mathrm{mp} 165-167^{\circ} \mathrm{C} ; R_{f}=0.44$ (EtOAc/hexanes 1:9); IR $\left(\mathrm{CH}_{2} \mathrm{Cl}_{2}\right.$, cast $) 3088,2969,2934,2198,2171,2136,1603,1518$, $1295 \mathrm{~cm}^{-1} ;{ }^{1} \mathrm{H}$ NMR $\left(500 \mathrm{MHz}, \mathrm{CDCl}_{3}\right) \delta 7.33(\mathrm{~d}, J=8.8 \mathrm{~Hz}, 4 \mathrm{H}), 6.74$ $(\mathrm{d}, J=8.8 \mathrm{~Hz}, 4 \mathrm{H}), 3.86$ (septet, $J=6.8 \mathrm{~Hz}, 4 \mathrm{H}), 1.28(\mathrm{~d}, J=6.8 \mathrm{~Hz}$, $24 \mathrm{H}), 0.26(\mathrm{~s}, 18 \mathrm{H}) \mathrm{ppm} ;{ }^{13} \mathrm{C} \mathrm{NMR}\left(125 \mathrm{MHz}, \mathrm{CDCl}_{3}\right.$, APT) $\delta 148.7$, $132.8,121.3,115.5,111.8,109.4,103.0,102.4,101.1,86.8,47.4,21.1$, -0.01 ppm; EIMS $m / z 618.4\left(\mathrm{M}^{+}, 26\right), 73.0\left(\left[\mathrm{SiMe}_{3}\right]^{+}, 76\right)$; HRMS calcd for $\mathrm{C}_{40} \mathrm{H}_{54} \mathrm{~N}_{2} \mathrm{Si}_{2}\left(\mathrm{M}^{+}\right)$618.3826, found 618.3823. Anal. Calcd for $\mathrm{C}_{40} \mathrm{H}_{54} \mathrm{~N}_{2} \mathrm{Si}_{2}$ : C, 77.61; H, 8.79; N, 4.53. Found: C, 77.61; H, 9.01; N, 4.68. 
iso-PDA 22. Compound $20(0.5466 \mathrm{~g}, 0.8830 \mathrm{mmol})$ was desilylated using $\mathrm{K}_{2} \mathrm{CO}_{3}(0.1220 \mathrm{~g}, 0.8830 \mathrm{mmol})$ and cross-coupled with vinyl triflate $12(0.8240 \mathrm{~g}, 1.766 \mathrm{mmol})$ in deoxygenated THF $(15 \mathrm{~mL})$ in the presence of $\mathrm{Pd}\left(\mathrm{PPh}_{3}\right)_{4}(0.05 \mathrm{~g}, 0.04 \mathrm{mmol}), i \mathrm{Pr}_{2} \mathrm{NH}(2 \mathrm{~mL})$, and $\mathrm{CuI}$ $(0.02 \mathrm{~g}, 0.09 \mathrm{mmol})$ according to general procedure B. Flash column chromatography (silica gel, EtOAc/hexanes 3:10) provided compound $22(0.74 \mathrm{~g}, 76 \%)$ as a red foam: $\mathrm{mp} 160-163{ }^{\circ} \mathrm{C} ; R_{f}=0.33$ (EtOAc/ hexanes 3:17); UV-vis $\left(\mathrm{CH}_{2} \mathrm{Cl}_{2}\right) \lambda_{\max }\left(\varepsilon \mathrm{L} \mathrm{mol}^{-1} \mathrm{~cm}^{-1}\right) 475$ (47300), 388 (22700), $318(49200) \mathrm{nm}$; fluorescence $\left(\mathrm{CH}_{2} \mathrm{Cl}_{2}, \lambda_{\text {exc }}=425 \mathrm{~nm}\right)$ $\lambda_{\text {max,em }}=609 \mathrm{~nm} ; \mathrm{IR}\left(\mathrm{CH}_{2} \mathrm{Cl}_{2}\right.$, cast $) 3083,3054,2956,2927,2207,2169$, $1603,1295 \mathrm{~cm}^{-1} ;{ }^{1} \mathrm{H}$ NMR $\left(500 \mathrm{MHz}, \mathrm{CD}_{2} \mathrm{Cl}_{2}\right) \delta 7.47-7.42(\mathrm{~m}, 8 \mathrm{H})$, $7.37-7.33(\mathrm{~m}, 6 \mathrm{H}), 7.29(\mathrm{~d}, J=9.1,4 \mathrm{H}), 7.27-7.23(\mathrm{~m}, 6 \mathrm{H}), 6.76(\mathrm{~d}$, $J=9.1 \mathrm{~Hz}, 4 \mathrm{H}), 3.90$ (septet, $J=6.9 \mathrm{~Hz}, 4 \mathrm{H}), 1.29(\mathrm{~d}, J=6.9 \mathrm{~Hz}, 24 \mathrm{H})$, $0.82(18 \mathrm{H}), 0.05(12 \mathrm{H}) \mathrm{ppm} ;{ }^{13} \mathrm{C} \mathrm{NMR}\left(125 \mathrm{MHz}, \mathrm{CD}_{2} \mathrm{Cl}_{2}\right) \delta 158.0$, $149.4,140.9,140.0,133.3,130.8,130.7,129.2,128.8,128.2,128.1,118.8$ 115.7, 111.6, 108.9, 103.8, 102.1, 101.7, 96.73, 96.65, 89.8, 87.0, 47.8, $26.2,21.2,16.9,-4.7 \mathrm{ppm}$; HRMS MALDI $m / z$ calcd for $\mathrm{C}_{78} \mathrm{H}_{86} \mathrm{~N}_{2} \mathrm{Si}_{2}$ $[\mathrm{M}]^{+} 1106.6324$, found 1106.6325 . DSC: $\mathrm{mp}=160{ }^{\circ} \mathrm{C}$.

Radialene 23. iso-PDA $22(0.310 \mathrm{~g}, 0.280 \mathrm{mmol})$ was desilylated using TBAF (0.62 mL, $0.62 \mathrm{mmol}, 1.0 \mathrm{M}$ in THF) and cross-coupled with dibromoolefin $7(0.153 \mathrm{~g}, 0.280 \mathrm{mmol})$ according to general procedure C. Flash column chromatography (silica gel, THF/hexanes, $3: 10 \rightarrow 3: 5)$ and recrystallization using $\mathrm{CH}_{2} \mathrm{Cl}_{2}$ /hexanes afforded 23 $(0.096 \mathrm{~g}, 27 \%)$ as a red solid: $\mathrm{mp} 235-237^{\circ} \mathrm{C}$ (discolors, dec); $R_{f}=$ (0.34 EtOAc/hexanes 3:17); UV-vis $\left(\mathrm{CH}_{2} \mathrm{Cl}_{2}\right) \lambda_{\max }\left(\varepsilon \mathrm{L} \mathrm{mol}^{-1} \mathrm{~cm}^{-1}\right)$ 544 (sh, 24300), 485 (sh, 32200), 438 (sh, 61900), 388 (76400), 295 $(48200) \mathrm{nm}$; Fluorescence $\left(\mathrm{CH}_{2} \mathrm{Cl}_{2}, \lambda_{\text {exc }}=425 \mathrm{~nm}\right) \lambda_{\text {max,em }}=656 \mathrm{~nm}$; IR $\left(\mathrm{CH}_{2} \mathrm{Cl}_{2}\right.$, cast $) 3084,3053,2962,2942,2865,2171,1603,1295 \mathrm{~cm}^{-1}$; ${ }^{1} \mathrm{H}$ NMR $\left(500 \mathrm{MHz}, \mathrm{CD}_{2} \mathrm{Cl}_{2}\right) \delta 7.45-7.42(\mathrm{~m}, 8 \mathrm{H}), 7.34-7.31(\mathrm{~m}$, $6 \mathrm{H}), 7.17-7.10(\mathrm{~m}, 6 \mathrm{H}), 7.04(\mathrm{~d}, J=9.1 \mathrm{~Hz}, 4 \mathrm{H}), 6.75(\mathrm{~d}, J=9.1 \mathrm{~Hz}$, $4 \mathrm{H}), 3.93$ (septet, $J=6.9 \mathrm{~Hz}, 4 \mathrm{H}), 1.32(\mathrm{~d}, J=6.9 \mathrm{~Hz}, 24 \mathrm{H}), 0.95-0.85$ $(\mathrm{m}, 42 \mathrm{H}) \mathrm{ppm} ;{ }^{13} \mathrm{C} \mathrm{NMR}\left(125 \mathrm{MHz}, \mathrm{CD}_{2} \mathrm{Cl}_{2}\right) \delta 153.2,149.3,140.3$, 140.2, 133.1, 131.05, 131.03, 129.7, 129.5, 128.24, 128.20, 117.1, 115.7, 114.0, 112.9, 111.7, 108.8, 104.4, 104.2, 103.14, 103.05, 102.0, 101.2, $96.7,96.3,86.6,47.9,21.2,18.8,11.5$ ppm. HRMS MALDI $m / z$ calcd for $\mathrm{C}_{90} \mathrm{H}_{98} \mathrm{~N}_{2} \mathrm{Si}_{2}[\mathrm{M}]^{+} 1262.7263$, found 1262.7266. DSC: dec $247{ }^{\circ} \mathrm{C}$ (onset), $289^{\circ} \mathrm{C}$ (peak).

A crystal suitable for X-ray crystallography was grown from a $\mathrm{CH}_{2} \mathrm{Cl}_{2}$ solution of $\mathbf{2 3}$ which had been layered with hexanes and allowed to slowly evaporate in the refrigerator at $4{ }^{\circ} \mathrm{C}$. X-ray crystallographic data for 23: $\mathrm{C}_{90} \mathrm{H}_{98} \mathrm{~N}_{2} \mathrm{Si}_{2}, M=1263.93$; monoclinic space group $P 2{ }_{1}$ (No. 4); $\rho_{\text {calcd }}=1.085 \mathrm{~g} \mathrm{~cm}^{-3} ; a=13.9906$ (7) $\AA, b=13.3080$ (6) $\AA, c=20.9613$ (10) $\AA ; \beta=97.6003(7)^{\circ} ; V=3868.4(3) \AA^{3} ; Z=2 ; \mu=0.091 \mathrm{~mm}^{-1}$. Final $R_{1}(\mathrm{~F})=0.0362$ (12506 observations) $\left[F_{0}^{2} \geq 2 \sigma\left(F_{0}^{2}\right)\right] ; w R_{2}=$ 0.0841 for 938 variables, 6 restraints, and 1470 data with $\left[F_{0}{ }^{2} \geq\right.$ $\left.-3 \sigma\left(F_{0}^{2}\right)\right]$; Largest diff. peak and hole 0.791 and $-0.717 \mathrm{e}^{-3}$. Within the disordered triisopropylsilyl group, the $\mathrm{Si} 2 \mathrm{~A}-\mathrm{C} 33 \mathrm{~A}$ and $\mathrm{Si} 2 \mathrm{~B}-\mathrm{C} 33 \mathrm{~B}$ distances were constrained to be equal (within $0.03 \AA$ ) during refinement. Also within this group, the C33A-C34A, C33A-C35A, C33B$\mathrm{C} 34 \mathrm{~B}$, and $\mathrm{C} 33 \mathrm{~B}-\mathrm{C} 35 \mathrm{~B}$ were constrained to be equal within (within $0.05 \AA$ A) during refinement. CCDC 1012586.

Radialene 24. Compound $23(0.025 \mathrm{~g}, 0.020 \mathrm{mmol})$ was desilylated and cross-coupled with 4-iodo- $N, N$-diisopropylaniline $(0.015 \mathrm{~g}$, $0.040 \mathrm{mmol})$ in the presence of $i \mathrm{Pr}_{2} \mathrm{NH}(2 \mathrm{~mL}), \mathrm{Pd}\left(\mathrm{PPh}_{3}\right)_{4}(0.001 \mathrm{~g}$, $0.001 \mathrm{mmol})$, and $\mathrm{CuI}(0.0004 \mathrm{~g}, 0.002 \mathrm{mmol})$ according to general procedure D. Silica gel filtration $\left(\mathrm{MeOH} / \mathrm{CH}_{2} \mathrm{Cl}_{2} 3: 100\right)$ and washing with $\mathrm{Et}_{2} \mathrm{O}$ afforded 24 as a red solid $(0.010 \mathrm{~g}, 40 \%)$ : mp $287{ }^{\circ} \mathrm{C}$ (discolors, dec); $R_{f}=0.31$ (THF/hexanes 3:7); UV-vis $\left(\mathrm{CH}_{2} \mathrm{Cl}_{2}\right) \lambda_{\max }$ $\left(\varepsilon \mathrm{L} \mathrm{mol}^{-1} \mathrm{~cm}^{-1}\right) 535$ (sh, 62000), 492 (75400), 410 (81500), 293 (73900); fluorescence $\left(\mathrm{CH}_{2} \mathrm{Cl}_{2}, \lambda_{\text {exc }}=425 \mathrm{~nm}\right) \lambda_{\text {max,em }}=650 \mathrm{~nm}$; IR $\left(\mathrm{CH}_{2} \mathrm{Cl}_{2}\right.$, cast $) 2954,2925,2171 \mathrm{~cm}^{-1} ;{ }^{1} \mathrm{H} \operatorname{NMR}\left(500 \mathrm{MHz}, \mathrm{CD}_{2} \mathrm{Cl}_{2}\right) \delta$ $7.50-7.49(\mathrm{dd}, J=8.5 \mathrm{~Hz}, J=8.3 \mathrm{~Hz}, 8 \mathrm{H}), 7.23-7.19(\mathrm{~m}, 8 \mathrm{H}), 7.12(\mathrm{tt}$, $J=7.4 \mathrm{~Hz}, J=1.5 \mathrm{~Hz}, 4 \mathrm{H}), 6.94(\mathrm{~d}, J=9.1 \mathrm{~Hz}, 8 \mathrm{H}), 6.70(\mathrm{~d}, J=9.1 \mathrm{~Hz}$, $8 \mathrm{H}), 3.92$ (septet, $J=6.8 \mathrm{~Hz}, 8 \mathrm{H}), 1.32(\mathrm{~d}, J=6.8, \mathrm{~Hz}, 48 \mathrm{H}) \mathrm{ppm} ;{ }^{13} \mathrm{C}$ NMR $\left(100 \mathrm{MHz}, \mathrm{CD}_{2} \mathrm{Cl}_{2}\right) \delta 152.0,149.3,140.4,133.2,131.1,129.4$, 128.3, 115.6, 113.8, 112.7, 108.8, 103.2, 102.5, 101.3, 97.4, 86.7, 47.8, $21.2 \mathrm{ppm}$. HRMS MALDI $\mathrm{m} / z$ calcd for $\mathrm{C}_{96} \mathrm{H}_{92} \mathrm{~N}_{4}[\mathrm{M}]^{+} 1300.7317$, found 1300.7312. DSC: dec, $271{ }^{\circ} \mathrm{C}$ (onset), $303{ }^{\circ} \mathrm{C}$ (peak).

Radialene 25. Compound 23 (0.026 g, $0.021 \mathrm{mmol}$ ) was desilylated and coupled with 4-iodobenzonitrile $(0.010 \mathrm{~g}, 0.042 \mathrm{mmol})$ in the presence of $i \mathrm{Pr}_{2} \mathrm{NH}(2 \mathrm{~mL}), \mathrm{Pd}\left(\mathrm{PPh}_{3}\right)_{4}(0.001 \mathrm{~g}, 0.001 \mathrm{mmol})$, and $\mathrm{CuI}$ $(0.0004 \mathrm{~g}, 0.002 \mathrm{mmol})$ according to general procedure $\mathrm{D}$. Flash column chromatography (silica gel, EtOAc/hexanes $1: 10 \rightarrow 3: 10$ ) afforded 25 as a brown solid $(0.0099 \mathrm{~g}, 41 \%): \mathrm{mp} 253-255^{\circ} \mathrm{C}$ (discolors, dec); $R_{f}=$ 0.48 (EtOAc/hexanes 3:7); UV-vis $\left(\mathrm{CH}_{2} \mathrm{Cl}_{2}\right) \lambda_{\max }\left(\varepsilon \mathrm{L} \mathrm{mol}^{-1} \mathrm{~cm}^{-1}\right)$ 573 (sh, 15000), 485 (64600), 403 (69900), 317 (60300); IR $\left(\mathrm{CH}_{2} \mathrm{Cl}_{2}\right.$, cast) $3054,2969,2919,2227,2170,1602,1294 \mathrm{~cm}^{-1} ;{ }^{1} \mathrm{H}$ NMR $\left(500 \mathrm{MHz}, \mathrm{CD}_{2} \mathrm{Cl}_{2}\right) \delta 7.57(\mathrm{~d}, J=8.6 \mathrm{~Hz}, 4 \mathrm{H}), 7.51-7.49(\mathrm{~m}, 4 \mathrm{H})$, 7.47-7.45 (m, 4H), 7.24-7.20 (m, 8H), 7.19-7.14 (m, 6H), 7.00-6.96 $(\mathrm{m}, 2 \mathrm{H}), 6.94(\mathrm{~d}, J=9.1 \mathrm{~Hz}, 4 \mathrm{H}), 6.69(\mathrm{~d}, J=9.1 \mathrm{~Hz}, 4 \mathrm{H}), 3.92$ (septet, $J=6.9 \mathrm{~Hz}, 4 \mathrm{H}), 1.32(\mathrm{~d}, J=6.9, \mathrm{~Hz}, 24 \mathrm{H}) \mathrm{ppm} ;{ }^{13} \mathrm{C} \mathrm{NMR}(125 \mathrm{MHz}$, $\left.\mathrm{CD}_{2} \mathrm{Cl}_{2}\right) \delta 154.0,149.3,140.3,139.8,133.2,132.7,132.3,131.14$, $131.08,129.9,129.7,128.4,128.2,127.0,120.2,118.7,115.5,114.5$, $112.6,112.0,109.2,108.5,106.6,102.5,102.0,101.8,97.8,96.6,95.9$, 90.2, 86.7, 47.8, $21.2 \mathrm{ppm}$; HRMS MALDI $\mathrm{m} / z$ calcd for $\mathrm{C}_{86} \mathrm{H}_{64} \mathrm{~N}_{4}$ $[\mathrm{M}]^{+} 1152.5126$, found 1152.5123 . DSC: $\operatorname{dec} 244{ }^{\circ} \mathrm{C}$ (onset), $251{ }^{\circ} \mathrm{C}$ (peak).

Radialene 26. Compound 23 (0.0258 g, $0.0204 \mathrm{mmol})$ was desilylated and cross-coupled with 4-iodonitrobenzene $(0.0102 \mathrm{~g}$, $0.0408 \mathrm{mmol})$ in the presence of $i \mathrm{Pr}_{2} \mathrm{NH}(2 \mathrm{~mL}), \mathrm{Pd}\left(\mathrm{PPh}_{3}\right)_{4}(0.001 \mathrm{~g}$, $0.001 \mathrm{mmol})$, and $\mathrm{CuI}(0.0004 \mathrm{~g}, 0.002 \mathrm{mmol})$ according to general procedure D. Silica gel filtration (EtOAc/hexanes 3:10) and washing with $\mathrm{Et}_{2} \mathrm{O}$ afforded 26 as a brown solid $\left(0.023 \mathrm{~g}\right.$, 94\%): $\mathrm{mp} 275-277^{\circ} \mathrm{C}$ (discolors, dec); $R_{f}=0.38$ (THF/hexanes 3:7); UV-vis $\left(\mathrm{CH}_{2} \mathrm{Cl}_{2}\right) \lambda_{\max }$ $\left(\varepsilon \mathrm{L} \mathrm{mol}^{-1} \mathrm{~cm}^{-1}\right) 582$ (sh, 12000), 497 (61300), 404 (67600), 300 (55400); IR $\left(\mathrm{CH}_{2} \mathrm{Cl}_{2}\right.$, cast) 3052, 2970, 2169, 1602, $1518 \mathrm{~cm}^{-1} .{ }^{1} \mathrm{H}$ NMR $\left(500 \mathrm{MHz}, \mathrm{CD}_{2} \mathrm{Cl}_{2}\right) \delta 8.13(\mathrm{~d}, J=9.0 \mathrm{~Hz}, 4 \mathrm{H}), 7.52-7.46(\mathrm{~m}$, $8 \mathrm{H}), 7.31(\mathrm{~d}, J=9.0 \mathrm{~Hz}, 4 \mathrm{H}), 7.24-7.15(\mathrm{~m}, 10 \mathrm{H}), 7.01-6.97(\mathrm{~m}, 2 \mathrm{H})$, $6.94(\mathrm{~d}, J=9.1 \mathrm{~Hz}, 4 \mathrm{H}), 6.69(\mathrm{~d}, J=9.1 \mathrm{~Hz}, 4 \mathrm{H}), 3.93$ (septet, $J=6.9 \mathrm{~Hz}$, $4 \mathrm{H}), 1.32(\mathrm{~d}, J=6.9 \mathrm{~Hz}, 24 \mathrm{H}) \mathrm{ppm} ;{ }^{13} \mathrm{C} \mathrm{NMR}\left(125 \mathrm{MHz}, \mathrm{CD}_{2} \mathrm{Cl}_{2}\right) \delta$ $154.2,149.4,147.8,140.3,139.8,133.2,133.1,131.2,131.1,129.9,129.8$, $129.0,128.4,128.3,123.8,120.7,115.5,114.5,111.9,108.9,108.5,107.0$, $102.5,102.0,101.8,97.8,96.3,95.9,91.0,86.7,47.9,21.2$ ppm; HRMS MALDI $m / z$ calcd for $\mathrm{C}_{84} \mathrm{H}_{64} \mathrm{~N}_{4} \mathrm{O}_{4}[\mathrm{M}]^{+} 1192.4922$, found 1192.4919 . DSC: $\operatorname{dec} 260{ }^{\circ} \mathrm{C}$ (onset), $270{ }^{\circ} \mathrm{C}$ (peak).

iso-PDA 27. iso-PDA $13(0.146 \mathrm{~g}, 0.167 \mathrm{mmol})$ was desilylated via reaction with $\mathrm{KOH}(0.014 \mathrm{~g}, 0.25 \mathrm{mmol})$ in $\mathrm{C}_{6} \mathrm{H}_{6}(15 \mathrm{~mL})$ at reflux for $25 \mathrm{~min}$. Aqueous workup and silica gel filtration $\left(\mathrm{CH}_{2} \mathrm{Cl}_{2} /\right.$ hexanes 3:20) provided the crude terminal diyne (ca. $0.095 \mathrm{~g}$, ca. $75 \%$ ) as a brown foam. The product was cross-coupled to 4-iodobenzonitrile $(0.060 \mathrm{~g}$, $0.26 \mathrm{mmol})$ in deoxygenated THF $(5 \mathrm{~mL})$ in the presence of $\mathrm{Pd}\left(\mathrm{PPh}_{3}\right)_{4}$ $(0.008 \mathrm{~g}, 0.007 \mathrm{mmol}), i \operatorname{Pr}_{2} \mathrm{NH}(2 \mathrm{~mL})$, and $\mathrm{CuI}(0.0025 \mathrm{~g}, 0.013$ mmol) at $40-50{ }^{\circ} \mathrm{C}$ for $18 \mathrm{~h}$. The reaction was cooled to rt, $\mathrm{Et}_{2} \mathrm{O}$ $(10 \mathrm{~mL})$ and $\mathrm{H}_{2} \mathrm{O}(5 \mathrm{~mL})$ were added, the organic phase was separated, washed with saturated aq $\mathrm{NH}_{4} \mathrm{Cl}(2 \times 50 \mathrm{~mL})$ and brine $(2 \times 50 \mathrm{~mL})$, dried $\left(\mathrm{MgSO}_{4}\right)$, and filtered, and the solvent was removed in vacuo. Flash column chromatography (silica gel $\mathrm{CH}_{2} \mathrm{Cl}_{2}$ /hexanes $3: 10 \rightarrow 1: 1$ ) followed by precipitation from hexanes afforded compound $27(0.091 \mathrm{~g}$, $57 \%$ from 13) as a yellow solid: $\mathrm{mp} 114-116^{\circ} \mathrm{C}$ (discolors, dec); $R_{f}=$ 0.37 (EtOAc/hexanes 3:17); UV-vis $\left(\mathrm{CH}_{2} \mathrm{Cl}_{2}\right) \lambda_{\max }(\varepsilon) 448$ (30900), 332 (63400), $250(49600) \mathrm{nm}$; fluorescence $\left(\mathrm{CH}_{2} \mathrm{Cl}_{2}, \lambda_{\mathrm{exc}}=425 \mathrm{~nm}\right)$ : $\lambda_{\text {max,em }}=538 \mathrm{~nm}$; IR $\left(\mathrm{CH}_{2} \mathrm{Cl}_{2}\right.$, cast $) 3056,2953,2928,2229,2175,2144$, $1603 \mathrm{~cm}^{-1} ;{ }^{1} \mathrm{H}$ NMR $\left(500 \mathrm{MHz}, \mathrm{CD}_{2} \mathrm{Cl}_{2}\right) \delta 7.61(\mathrm{~d}, J=8.7 \mathrm{~Hz}, 4 \mathrm{H})$, $7.50(\mathrm{~d}, J=8.7 \mathrm{~Hz}, 4 \mathrm{H}), 7.46-7.43(\mathrm{~m}, 4 \mathrm{H}), 7.40-7.36(\mathrm{~m}, 10 \mathrm{H})$, 7.26-7.21 (m, 6H), $0.82(\mathrm{~s}, 18 \mathrm{H}), 0.02(\mathrm{~s}, 12 \mathrm{H}) \mathrm{ppm} ;{ }^{13} \mathrm{C}$ NMR $\left(125 \mathrm{MHz}, \mathrm{CD}_{2} \mathrm{Cl}_{2}\right) \delta 160.0,140.4,139.9,132.8,132.5,130.75,130.69$, $129.6,129.3,128.3,128.2,127.2,119.8,118.7,114.8,112.7,103.2,101.4$, 100.0, 97.5, 97.2, 90.4, 88.6, 26.2, 16.9, $-4.8 \mathrm{ppm}$. HRMS MALDI $\mathrm{m} / \mathrm{z}$ calcd for $\mathrm{C}_{68} \mathrm{H}_{58} \mathrm{~N}_{2} \mathrm{Si}_{2}\left(\mathrm{M}^{+}\right)$958.4133, found 958.4131.

iso-PDA 28. iso-PDA $13(0.1032 \mathrm{~g}, 0.1182 \mathrm{mmol})$ was desilylated via reaction with $\mathrm{KOH}(0.010 \mathrm{~g}, 0.18 \mathrm{mmol})$ in $\mathrm{C}_{6} \mathrm{H}_{6}(15 \mathrm{~mL})$ at reflux for $25 \mathrm{~min}$. Aqueous workup and silica gel filtration $\left(\mathrm{CH}_{2} \mathrm{Cl}_{2} /\right.$ hexanes 3:20) provided the crude terminal diyne (ca. $0.08 \mathrm{~g}$, ca. $88 \%$ ) as a brown foam. This product was cross-coupled to 4-iodonitrobenzene $(0.050 \mathrm{~g}$, $0.20 \mathrm{mmol})$ in deoxygenated THF $(5 \mathrm{~mL})$ in the presence of $\mathrm{Pd}\left(\mathrm{PPh}_{3}\right)_{4}$ $(0.006 \mathrm{~g}, 0.005 \mathrm{mmol}), i \mathrm{Pr}_{2} \mathrm{NH}(2 \mathrm{~mL})$, and $\mathrm{CuI}(0.002 \mathrm{~g}, 0.01 \mathrm{mmol})$ at $40-50{ }^{\circ} \mathrm{C}$ for $18 \mathrm{~h}$. The reaction was cooled to rt, $\mathrm{Et}_{2} \mathrm{O}(10 \mathrm{~mL})$ and $\mathrm{H}_{2} \mathrm{O}(5 \mathrm{~mL})$ were added, the organic phase was separated, washed with saturated aq $\mathrm{NH}_{4} \mathrm{Cl}(2 \times 50 \mathrm{~mL})$ and brine $(2 \times 50 \mathrm{~mL})$, dried $\left(\mathrm{MgSO}_{4}\right)$, and filtered, and the solvent was removed in vacuo. Flash 
column chromatography (silica gel, $\mathrm{CH}_{2} \mathrm{Cl}_{2} 1: 1$ ) followed by precipitation from hexanes afforded compound $28(0.070 \mathrm{~g}, 59 \%$ from 13$)$ as an orange solid: $\mathrm{mp} 161-162{ }^{\circ} \mathrm{C} . R_{f}=0.47$ (EtOAc/hexanes, 3:17). UV-vis $\left(\mathrm{CH}_{2} \mathrm{Cl}_{2}\right) \lambda_{\max }(\varepsilon) 459$ (27300), 327 (42600), 249 (39500) nm; fluorescence $\left(\mathrm{CH}_{2} \mathrm{Cl}_{2}, \lambda_{\text {exc }}=425 \mathrm{~nm}\right): \lambda_{\text {max }, \text { em }}=566 \mathrm{~nm} ; \mathrm{IR}\left(\mathrm{CH}_{2} \mathrm{Cl}_{2}\right.$, cast) $3055,2953,2928,2175,2144,1341 \mathrm{~cm}^{-1}$; ${ }^{1} \mathrm{H}$ NMR (400 MHz, $\left.\mathrm{CD}_{2} \mathrm{Cl}_{2}\right) \delta 8.17(\mathrm{~d}, J=8.9 \mathrm{~Hz}, 4 \mathrm{H}), 7.58(\mathrm{~d}, J=8.9 \mathrm{~Hz}, 4 \mathrm{H}), 7.48-7.45$ $(\mathrm{m}, 4 \mathrm{H}), 7.41-7.36(\mathrm{~m}, 10 \mathrm{H}), 7.26-7.22(\mathrm{~m}, 6 \mathrm{H}), 0.82(\mathrm{~s}, 18 \mathrm{H}), 0.02$ (s, 12H) ppm; ${ }^{13} \mathrm{C}$ NMR $\left(100 \mathrm{MHz}, \mathrm{CD}_{2} \mathrm{Cl}_{2}\right) \delta 160.0,147.8,140.3$, 139.8 , 133.1, 130.75, 130.70, 129.6, 129.4, 129.1 128.20, 123.9, 120.4, 114.5, 103.1, 101.3, 100.4, 97.5, 96.9, 91.1, 90.2 88.6, 26.1, 16.9, $-4.8 \mathrm{ppm}$. HRMS MALDI $\mathrm{m} / \mathrm{z}$ calcd for $\mathrm{C}_{66} \mathrm{H}_{58} \mathrm{~N}_{2} \mathrm{O}_{4} \mathrm{Si}_{2}\left(\mathrm{M}^{+}\right)$, 998.3930 found 998.3930. DSC: $\mathrm{mp}=164{ }^{\circ} \mathrm{C}$.

\section{ASSOCIATED CONTENT}

\section{S Supporting Information}

${ }^{1} \mathrm{H}$ and ${ }^{13} \mathrm{C}$ NMR spectra for new compounds, selected UV-vis and emission traces, and computational details. This material is available free of charge via the Internet at http://pubs.acs.org.

\section{AUTHOR INFORMATION}

\section{Corresponding Authors}

*E-mail: nuranelmaci@iyte.edu.tr.

*E-mail: rik.tykwinski@fau.de.

\section{Author Contributions}

${ }^{\perp}$ S.R. and S.K. contributed equally to this work.

\section{Notes}

The authors declare no competing financial interest.

\section{ACKNOWLEDGMENTS}

We are grateful for funding from NSERC, the Deutsche Forschungsgemeinschaft (DFG-SFB 953, "Synthetic Carbon Allotropes"), the Interdisciplinary Center for Molecular Materials (ICMM), and the "Excellence Initiative" supporting the Cluster of Excellence "Engineering of Advanced Materials" (www.eam.uni-erlangen.de). We thank Prof. Talat Yalcin for use of the computer facilities at the Biological Mass Spectrometry and Proteomics Laboratory financially supported by The State Planning Organization (Turkey), DPT (Project No. 2008K120730).

\section{REFERENCES}

(1) Carbon-Rich Compounds: Molecules to Materials; Haley, M. M., Tykwinski, R. R., Eds.; Wiley-VCH: Weinheim, 2006.

(2) Modern Supramolecular Chemistry; Diederich, F., Stang, P. J., Tykwinski, R., Eds.; Wiley-VCH: Weinheim, 2008.

(3) Diederich, F.; Kivala, M. Adv. Mater. 2010, 22, 803-812.

(4) Haley, M. M. Pure Appl. Chem. 2008, 80, 519-532.

(5) Rivera-Fuentes, P.; Diederich, F. Angew. Chem., Int. Ed. 2012, 51, $2818-2828$.

(6) Gross, D. E.; Zang, L.; Moore, J. S. Pure Appl. Chem. 2012, 84, 869878.

(7) Iyoda, M.; Yamakawa, J.; Rahman, M. J. Angew. Chem., Int. Ed. 2011, 50, 10522-10553.

(8) Maraval, V.; Chauvin, R. Chem. Rev. 2006, 106, 5317-5343.

(9) Gholami, M.; Tykwinski, R. R. Chem. Rev. 2006, 106, 4997-5027.

(10) Geneste, F.; Moradpour, A. Org. Prep. Proced. Int. 1999, 31, 507536.

(11) Hopf, H.; Maas, G. Angew. Chem., Int. Ed. Engl. 1992, 31, 931954.

(12) Hopf, H.; Maas, G. In The Chemistry of Dienes and Polyenes; Rappoport, Z., Ed.; Wiley: Chichester, 1997; Vol. 1; pp 927-977.

(13) Diederich, F. Chem. Commun. 2001, 219-227.

(14) Diederich, F. Chimia 2001, 55, 821-827.

(15) Diederich, F. Nature (London) 1994, 369, 199-207.
(16) Diederich, F. Pure Appl. Chem. 1999, 71, 265-273.

(17) Boldi, A. M.; Diederich, F. Angew. Chem., Int. Ed. Engl. 1994, 33, $468-471$.

(18) Nielsen, M. B.; Schreiber, M.; Baek, Y. G.; Seiler, P.; Lecomte, S.; Boudon, C.; Tykwinski, R. R.; Gisselbrecht, J.-P.; Gramlich, V.; Skinner, P. J.; Bosshard, C.; Günter, P.; Gross, M.; Diederich, F. Chem.-Eur. J. 2001, 7, 3263-3280.

(19) Mitzel, F.; Boudon, C.; Gisselbrecht, J. P.; Seiler, P.; Gross, M.; Diederich, F. Helv. Chim. Acta 2004, 87, 1130-1157.

(20) Kivala, M.; Mitzel, F.; Boudon, C.; Gisselbrecht, J.-P.; Seiler, P.; Gross, M.; Diederich, F. Chem.-Asian J. 2006, 1, 479-489.

(21) Bandyopadhyay, A.; Varghese, B.; Hopf, H.; Sankararaman, S. Chem.-Eur. J. 2007, 13, 3813-3821.

(22) Gholami, M.; Chaur, M. N.; Wilde, M.; Ferguson, M. J.; McDonald, R.; Echegoyen, L.; Tykwinski, R. R. Chem. Commun. 2009, 3038-3040.

(23) Chen, G.; Dawe, L.; Wang, L.; Zhao, Y. Org. Lett. 2009, 11, $2736-$ 2739.

(24) Wu, Y.-L.; Bures, F.; Jarowski, P. D.; Schweizer, W. B.; Boudon, C.; Gisselbrecht, J. P.; Diederich, F. Chem.-Eur. J. 2010, 16, 95929605.

(25) Lincke, K.; Frellsen, A. F.; Parker, C. R.; Bond, A. D.; Hammerich, O.; Nielsen, M. B. Angew. Chem., Int. Ed. 2012, 51, 6099-6102.

(26) Hasegawa, M.; Takatsuka, Y.; Kuwatani, Y.; Mazaki, Y. Tetrahedron Lett. 2012, 53, 5385-5388.

(27) Benzoid derivatives using the same concept of a linear- and crossconjugated framework to mediate $\pi$-electron communication have been recently described; for examples, see: (a) Leu, W. C. W.; Fritz, A. E.; Digianantonio, K. M.; Hartley, C. S. J. Org. Chem. 2012, 77, 2285-2298. (b) Dickson-Karn, N. M.; Olson, C. M.; Leu, W. C. W.; Hartley, C. S. J. Phys. Org. Chem. 2014, 27, 661-669.

(28) Gholami, M.; Ramsaywack, S.; Chaur, M. N.; Murray, A. H.; McDonald, R.; Ferguson, M. J.; Echegoyen, L.; Tykwinski, R. R. Chem.-Eur. J. 2013, 19, 15120-15132.

(29) Gholami, M.; Melin, F.; McDonald, R.; Ferguson, M.; Echegoyen, L.; Tykwinski, R. R. Angew. Chem., Int. Ed. 2007, 46, 9081-9085.

(30) Eisler, S.; Tykwinski, R. R. Angew. Chem., Int. Ed. 1999, 38, 19401943.

(31) van der Veen, M. H.; Rispens, M. T.; Jonkman, H. T.; Hummelen, J. C. Adv. Funct. Mater. 2004, 14, 215-223.

(32) Opsitnick, E.; Lee, D. Chem.—Eur. J. 2007, 13, 7040-7049.

(33) Gubler, U.; Spreiter, R.; Bosshard, C.; Günter, P.; Tykwinski, R. R.; Diederich, F. Appl. Phys. Lett. 1998, 73, 2396-2398.

(34) Coe, B. J.; Fielden, J.; Foxon, S. P.; Helliwell, M.; Asselberghs, I.; Clays, K.; De Mey, K.; Brunschwig, B. S. J. Org. Chem. 2010, 75, 85508563.

(35) Ohta, K.; Yamada, S.; Kamada, K.; Slepkov, A. D.; Hegmann, F. A.; Tykwinski, R. R.; Shirtcliff, L. D.; Haley, M. M.; Salek, P.; Gel'mukhanov, F.; Agren, H. J. Phys. Chem. A 2011, 115, 105-117.

(36) Spitler, E. L.; Haley, M. M. Org. Biomol. Chem. 2008, 6, 15691576.

(37) Detert, H.; Lehmann, M.; Meier, H. Materials 2010, 3, 32183330.

(38) van Walree, C. A.; van der Wiel, B. C.; Williams, R. M. Phys. Chem. Chem. Phys. 2013, 15, 15234-15242.

(39) Zucchero, A. J.; McGrier, P. L.; Bunz, U. H. F. Acc. Chem. Res. 2010, 43, 397-408.

(40) Limacher, P. A.; Lüthi, H. P. WIREs Comput. Mol. Sci. 2011, 1, 477-486.

(41) Hopf, H.; Sherburn, M. S. Angew. Chem., Int. Ed. 2012, 51, 22982338.

(42) Throughout this manuscript, donor-acceptor (D-A) denotes the presence of a donor and an accepter moiety, while donor/acceptor (D/A) indicates a donor or an acceptor moiety.

(43) Kivala, M.; Diederich, F. Acc. Chem. Res. 2009, 42, 235-248.

(44) Nielsen, S. B.; Nielsen, M. B.; Rubio, A. Acc. Chem. Res. 2014, 47, 1417-1425.

(45) Tykwinski, R. R.; Diederich, F. Liebigs Ann./Recueil 1997, 649661. 
(46) Ciulei, S. C.; Tykwinski, R. R. Org. Lett. 2000, 2, 3607-3610.

(47) Zhao, Y.; Slepkov, A. D.; Akoto, C. O.; McDonald, R.; Hegmann,

F. A.; Tykwinski, R. R. Chem.-Eur. J. 2005, 11, 321-329.

(48) Sonogashira, K.; Tohda, Y.; Hagihara, N. Tetrahedron Lett. 1975, $4467-4470$

(49) Chinchilla, R.; Najera, C. Chem. Rev. 2007, 107, 874-922.

(50) Lange, T.; van Loon, J.-D.; Tykwinski, R. R.; Schreiber, M.; Diederich, F. Synthesis 1996, 537-550.

(51) For a synthesis of a similar TEE, see: Anthony, J.; Boldi, A. M.; Rubin, Y.; Hobi, M.; Gramlich, V.; Knobler, C. B.; Seiler, P.; Diederich, F. Helv. Chim. Acta 1995, 78, 13-45.

(52) Haven, S. J.; Hergenrother, P. M. J. Org. Chem. 1985, 50, 17631765.

(53) Kukula, H.; Veit, S.; Godt, A. Eur. J. Org. Chem. 1999, 277-286.

(54) Krebs, A.; Wilke, J. Top. Curr. Chem. 1983, 109, 189-233.

(55) Tykwinski, R. R.; Hilger, A.; Diederich, F.; Luthi, H. P.; Seiler, P.; Gramlich, V.; Gisselbrecht, J. P.; Boudon, C.; Gross, M. Helv. Chim. Acta 2000, 83, 1484-1508.

(56) The difference in $\lambda_{\max }$ is more easily appreciated when the signals are normalized, and this spectrum is provided as Supporting Information, Figure S2.

(57) This is perhaps due to the symmetry of the conjugated framework, although a complete understanding of this observation is outside the scope of the work described herein. Absorption trends in conjugated macrocycles as a function of symmetry have been described for cyclic oligothiophenes; see: (a) Bhaskar, A.; Ramakrishna, G.; Hagedorn, K.; Varnavski, O.; Mena-Osteritz, E.; Bäuerle, P.; Goodson, T., III. J. Phys. Chem. B 2007, 111, 946-954. (b) Bednarz, M.; Reineker, P.; MenaOsteritz, E.; Bäuerle, P. J. Lumin. 2004, 110, 225-231.

(58) Emission of, for example, 23 and 24, does not vary as a function of excitation wavelength $\left(\lambda_{\text {exc }}=364,385\right.$, or $\left.400 \mathrm{~nm}\right)$.

(59) Tykwinski, R. R.; Schreiber, M.; Carlon, R. P.; Diederich, F.; Gramlich, V. Helv. Chim. Acta 1996, 79, 2249-2281.

(60) Spitler, E. L.; Shirtcliff, L. D.; Haley, M. M. J. Org. Chem. 2007, 72, $86-96$.

(61) Yanai, T.; Tew, D.; Handy, N. Chem. Phys. Lett. 2004, 393, 51-57. (62) Gaussian 09, Revision A.02: Frisch, M. J.; Trucks, G. W.; Schlegel, H. B.; Scuseria, G. E.; Robb, M. A.; Cheeseman, J. R.; Scalmani, G.; Barone, V.; Mennucci, B.; Petersson, G. A.; Nakatsuji, H.; Caricato, M.; Li, X.; Hratchian, H. P.; Izmaylov, A. F.; Bloino, J.; Zheng, G.; Sonnenberg, J. L.; Hada, M.; Ehara, M.; Toyota, K.; Fukuda, R.; Hasegawa, J.; Ishida, M.; Nakajima, T.; Honda, Y.; Kitao, O.; Nakai, H.; Vreven, T.; Montgomery, J. A., Jr.; Peralta, J. E.; Ogliaro, F.; Bearpark, M.; Heyd, J. J.; Brothers, E.; Kudin, K. N.; Staroverov, V. N.; Kobayashi, R.; Normand, J.; Raghavachari, K.; Rendell, A.; Burant, J. C.; Iyengar, S. S.; Tomasi, J.; Cossi, M.; Rega, N.; Millam, N. J.; Klene, M.; Knox, J. E.; Cross, J. B.; Bakken, V.; Adamo, C.; Jaramillo, J.; Gomperts, R; Stratmann, R. E.; Yazyev, O.; Austin, A. J.; Cammi, R.; Pomelli, C.; Ochterski, J. W.; Martin, R. L.; Morokuma, K.; Zakrzewski, V. G.; Voth, G. A.; Salvador, P.; Dannenberg, J. J.; Dapprich, S.; Daniels, A. D.; Farkas, Ö.; Foresman, J. B.; Ortiz, J. V.; Cioslowski, J.; Fox, D. J. Gaussian, Inc., Wallingford, CT, 2009.

(63) Choi, H. C.; Kertesz, M.; Karpfen, A. J. Chem. Phys. 1997, 107, 6712-6721.

(64) Champagne, B.; Perpète, E. A.; Jacquemin, D.; van Gisbergen, S. J. A.; Baerends, E.-J.; Soubra-Ghaoui, C.; Robins, K. A.; Kirtman, B. J. Phys. Chem. A 2000, 104, 4755-4763.

(65) Limacher, P. A.; Mikkelsen, K. V.; Lüthi, H. P. J. Chem. Phys. 2009, 130, 194114.

(66) Peach, M. J. G.; Tellgren, E. I.; Salek, P.; Helgaker, T.; Tozer, D. J. J. Phys. Chem. A 2007, 111, 11930-11935.

(67) It is interesting to note that in the corresponding "un-expanded" 4-radialene, the LUMO shows no node between the four ring carbon atoms; i.e., this part of the orbital is bonding throughout the ring. See Figure S1 (Supporting Information). 